San Jose State University

SJSU ScholarWorks

Doctoral Projects

Master's Theses and Graduate Research

Spring 5-1-2015

\title{
Heath Care Providers' Perceptions of the Reproductive Challenges and Experiences among Asian Indian Women Living in Silicon Valley
}

Olga Alexandra Libova

Northern California Consortium, Doctor of Nursing Practice Program, California State University, Fresno and San José State University

Follow this and additional works at: https://scholarworks.sjsu.edu/etd_doctoral

Part of the Maternal, Child Health and Neonatal Nursing Commons, and the Nursing Midwifery Commons

\section{Recommended Citation}

Libova, Olga Alexandra, "Heath Care Providers' Perceptions of the Reproductive Challenges and Experiences among Asian Indian Women Living in Silicon Valley" (2015). Doctoral Projects. 6. DOI: https://doi.org/10.31979/etd.5nn2-r6ap https://scholarworks.sjsu.edu/etd_doctoral/6

This Doctoral Project is brought to you for free and open access by the Master's Theses and Graduate Research at SJSU ScholarWorks. It has been accepted for inclusion in Doctoral Projects by an authorized administrator of SJSU ScholarWorks. For more information, please contact scholarworks@sjsu.edu. 


\title{
HEATH CARE PROVIDERS' PERCEPTIONS OF THE REPRODUCTIVE CHALLENGES AND EXPERIENCES AMONG ASIAN INDIAN WOMEN LIVING IN SILICON VALLEY
}

\author{
by \\ Olga Alexandra Libova
}

\author{
A doctoral project submitted in partial \\ fulfillment of the requirements for the degree of \\ Doctor of Nursing Practice in the
}

California State University, Northern California Consortium, Doctor of Nursing Practice Program, California State University, Fresno

April 2015 


\begin{abstract}
HEATH CARE PROVIDERS' PERCEPTIONS OF THE REPRODUCTIVE CHALLENGES AND EXPERIENCES AMONG ASIAN INDIAN WOMEN LIVING IN SILICON VALLEY
\end{abstract}

Objective: To identify common reproductive challenges among Asian Indian (AI) women living in Silicon Valley as perceived by healthcare providers (HCP).

Design: A 71-item investigator-developed survey

Setting: The survey was available on-line to all HCPs in California Santa Clara county, $75 \%$ of respondents were affiliated with El Camino Hospital Mountain View.

Participants: Convenience sample of 78 respondents: $34 \%$ mother-baby nurses, $24 \%$ labor-delivery nurses, $21 \% \mathrm{OB} / \mathrm{GYNs}, 7 \% \mathrm{CNMs}, 14 \%$ other $\mathrm{HCP}$; $89 \%$ female; $55 \%$ Caucasian, 24\% Asian.

Methods: Likert-type scales comparing prevalence of certain reproductive challenges among AI women and women from other race-ethnic groups and openended questions regarding HCPs' experience caring for AI women.

Results: AI women seeking reproductive services in Silicon Valley are more likely than women from other race ethnic groups to experience unconsummated marriages, vaginismus, and difficulty tolerating pelvic exams. They are also more likely to lack of knowledge about sex and reproduction. AI women exhibited increased anxiety around pregnancy, birth, breastfeeding, newborn care, as well as reluctance to enroll in classes or prepare a birth plan. Nurses found clients' lack of understanding of the training and function of the nurses in the United States, as well as AI patients' families' large role decisionmaking, to be obstacles to establishing therapeutic relationship with AI patients.

Conclusion: HCPs need to be aware of prevalence of vaginismus in AI women. Culturally competent prenatal classes addressing identified reproductive challenges of AI women need to be developed and expectant parents and family members need to be encouraged to participate. HCPs need to be educated on culturally competent care to AI patients. 


\section{APPROVED}

For the Department of Nursing:

We, the undersigned, certify that the thesis of the following student meets the required standards of scholarship, format, and style of the university and the student's graduate degree program for the awarding of the Doctor of Nursing Practice degree.

\section{Olga Alexandra Libova}

Deepika Goyal (Chair) $0.9 \mathrm{ag}$

Kenneth Weber (Committee member)

Mary Buxton (Committee member)

For the University Graduate Committee:

Dean, Division of Graduate Studies 


\section{AUTHORIZATION FOR REPRODUCTION OF DISSERTATION}

X I grant permission for the reproduction of this thesis in part or in its entirety without further authorization from me, on the condition that the person or agency requesting reproduction absorbs the cost and provides proper acknowledgment of authorship.

Permission to reproduce this thesis in part or in its entirety must be obtained from me.

Signature of thesis author: 


\section{DEDICATION}

This dissertation is dedicated to my parents Dr. Lucy Libova and Dr.

Alexander Leyzerovich, who were working on their dissertations all through my childhood and instilled the belief that a dissertation is just something that you do at some point of your life. They supported me and took care of my kids through my journey from an engineer to a DNP-prepared midwife and nursing faculty, trusting me to make the right decisions for myself and my family.

\section{ACKNOWLEDGMENTS}

First, I would like to thank my family, especially my daughter Ari, my biggest cheerleader, for their support and encouragement during this long journey.

I would like to thank my program advisor Ruth Rosenblum, DNP, my project chair Deepika Goyal, $\mathrm{PhD}$ and my doctoral committee members Mary Buxton, LCSW and Ken Weber, MD for their guidance and support.

I would like to thank my colleagues who answered the survey and provided me with valuable information for this research. 


\section{TABLE OF CONTENTS}

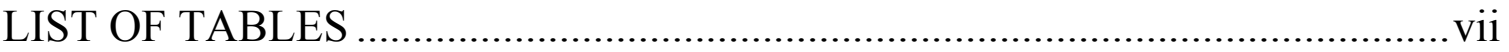

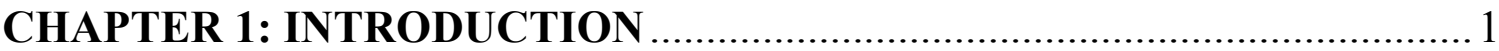

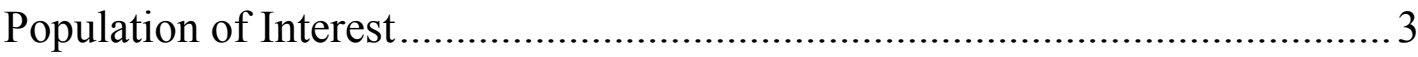

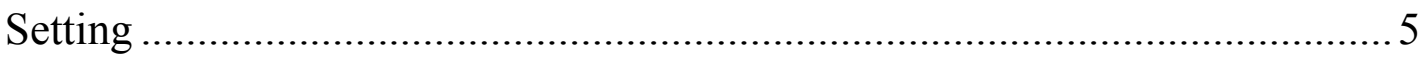

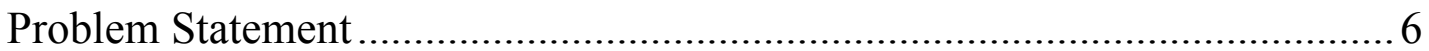

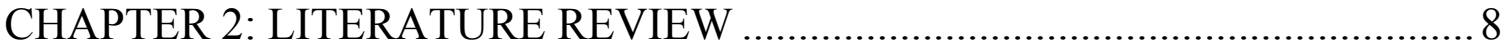

Asian Indian Women: Experiences of Health Care Providers........................... 8

Asian Indian Women: Marital and Sexual Relationships ................................ 11

Asian Indian Women: Pregnancy, Birth, and Breastfeeding .......................... 15

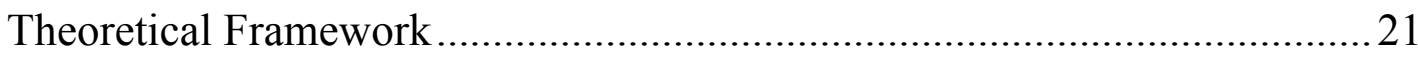

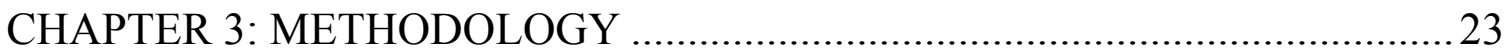

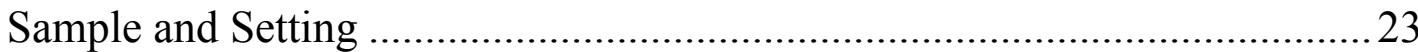

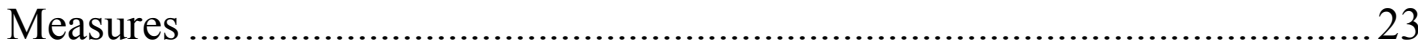

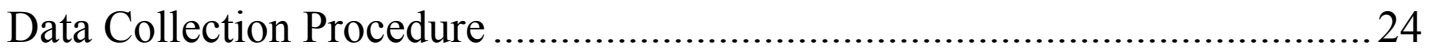

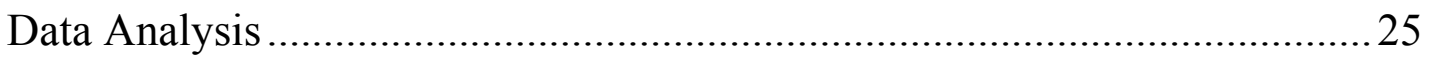

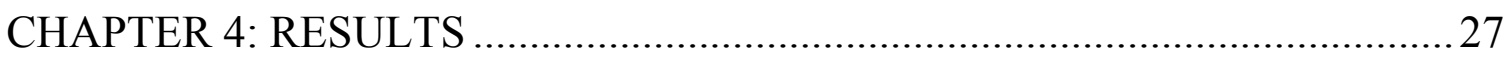

Research Question 1: Description of AI Patients in Silicon Valley ...............29

Research Question 2: Prevalence of Certain Challenges and Experiences in AI Women Compared to Women from Other Race-Ethnic Groups.

Research Question 3: What are Specific Challenges for Healthcare Professionals Caring for Asian Indian Women in a Reproductive/Perinatal Setting.

CHAPTER 5: DISCUSSION AND CONCLUSION ...........................................48

Perception of Asian Indian patients and their families ...................................48 


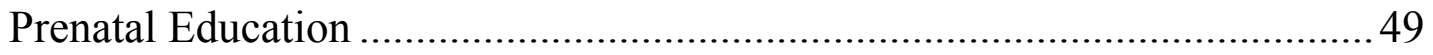

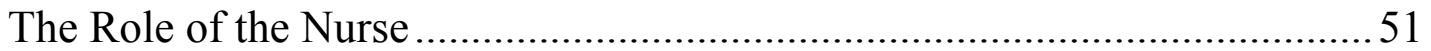

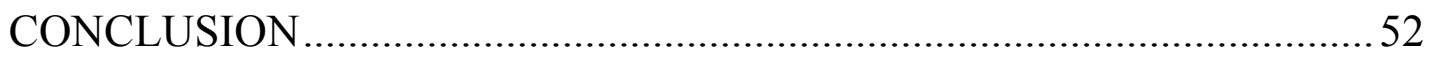

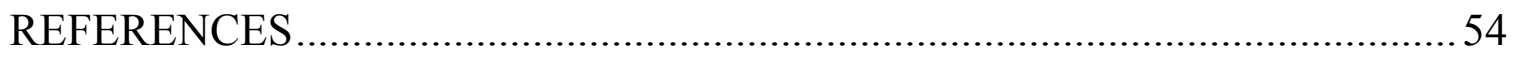

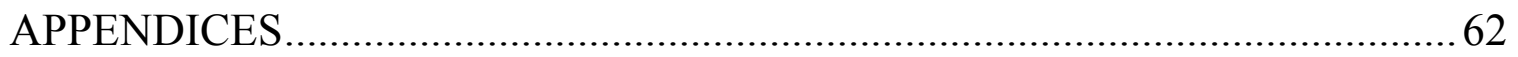

APPENDIX A: INVITATION TO PARTICIPATE IN THE STUDY .................63

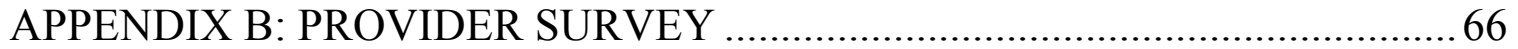




\section{LIST OF TABLES}

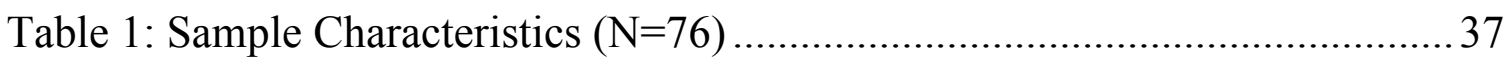

Table 2. Percentage of AI Patients in Respondents' Practice ...................................39

Table 3. Distribution of Answers to Four Sections by Professional Role. ............ 39

Table 4. Most Significant Trends in Likert-scale Questions....................................40 


\section{REPRODUCTIVE CHALLENGES OF ASIAN INDIAN WOMEN}

\section{CHAPTER 1: INTRODUCTION}

In a 2001 report, "Crossing the Quality Chasm," the Institute of Medicine identified patient-centered care as one of the six core needs of the U. S. healthcare system. Initiatives to promote patient-centered care focus on improving the relationship between patients and health care providers (HCPs) and making the healthcare system more responsive to patients' needs and preferences. To deliver individualized patient-centered care, a provider must be aware and respectful of the diversity of patients' perspectives. In 2002, the Institute of Medicine emphasized the importance of cultivating cultural competence among healthcare providers in order to eliminate racial/ethnic disparities in healthcare. Beach, Saha, and Cooper (2006) concluded that cultural competence enhances the ability of health care systems and providers to address individual patients' preferences and goals, and Campinha-Bacote (2011) suggested that cultural competence can be viewed as a necessary set of skills for nurses to develop in order to provide effective patient-centered care.

Pregnancy and childbirth are universal human experiences, largely affected and predetermined by culture (Ottani, 2002). Many authors have discussed the importance of educating healthcare professionals regarding culturally competent care and expectations around childbirth to help them deliver culturally congruent perinatal care (Callister, 1995; Spitzer; 2007; Wilson, 2012). Yet, to date, studies

of healthcare professionals caring for ethnic and cultural minority (ECM) women have focused primarily on the subjective experiences and educational needs of nurses and midwives (Boi, 2000; Cioffi, 2004; Vydelingum, 2006). Existing research has placed little emphasis on asking healthcare providers about the best way to help ECM women have a positive, healthy, and empowering pregnancy 
and birth experience. Reproductive HCPs delivering care to ECM women are uniquely positioned to identify their clients' culturally specific needs and find ways to meet those needs, but no studies to date have investigated HCPs' perceptions regarding the needs of ECM women in North American healthcare institutions. New information regarding common challenges and potential cultural conflicts inherent in caring for ECM women would help guide culturally congruent perinatal patient education and care, as well as allow HCPs to close the gap between what patients expect from the healthcare system and what the healthcare system expects from the patients.

This study focuses on the reproductive experiences and challenges of Asian Indian (AI) women in the southern San Francisco Bay Area (also known as Silicon Valley), as perceived by their reproductive healthcare professionals. AI women who have come to the Silicon Valley during the past fifteen years are a unique immigrant population, whose needs, challenges, and experiences have not been previously described in literature.

To date, much of the literature regarding immigrant health has focused on the needs and experiences of non-English speaking, minimally educated, financially disadvantaged populations, who often lack access to healthcare and must deal with cultural differences and a language barrier when engaging with the U.S. healthcare system (Assanand, Dias, Richardson, Chambers, \& WaxierMorrison, 2005). In 2001, Bottorff et al. identified the need to better understand the specific health concerns of immigrant South Asian women, including the ways in which South Asian women conceptualize and talk about their care. However, few have researched the healthcare challenges facing typical representatives of "model minorities," such as Asian communities, who typically have high levels of education, income, and access to care. 


\section{Population of Interest}

Asian Indians in the United States form a diverse group of individuals who claim their ancestry in the Indian subcontinent. They are often described in literature as a part of a larger group, the South Asians, and are also referred to as South Asian Americans ( Patel, 2007; Botorff, et al., 2001).

According to the 2010 U.S. Census, AIs comprise the third largest group among Asians living in the United States. Between 2000 and 2010, the population of AIs in the United States increased by $69 \%$ and totaled more than 2.8 million people by 2010 (South Asian Americans Leading Together [SAALT], 2012).

Eighty-seven percent of AIs over the age of 18 living in the United States reported being born outside of the United States, and $89 \%$ of AIs reported no other race or ethnicity — one of the highest percentages among Asian groups (U.S. Census, 2010). During 2008-2010, 14\% of AI newlyweds in the United States married a non-Indian, according to the 2012 Pew Charitable Trust Report. For other Asian American groups, intermarriages are significantly more common: 35\% for Chinese, 54\% for Filipino and 64\% for Japanese. Dasgupta (1998) observed that AIs in the United States have "tried fiercely to maintain a sense of ethnic selfidentity against the assimilatory forces of the US" (p. 954). This data shows AIs to be one of the most homogenous large Asian diaspora groups in the United States, and suggests that they may be less prone to assimilation. As a result, AIs living in the United States are more likely to be influenced by the cultural traditions of their native country than other Asian diaspora groups.

As of 2010, California was home to $19 \%$ of the country's AI population-a higher percentage than any other U.S. state (U.S. Census, 2010). The booming tech industry of the Silicon Valley, located primarily in California's Santa Clara County, has attracted growing numbers of young Indian engineers and their 
REPRODUCTIVE CHALLENGES OG ASIAN INDIAN WOMEN

families. According to the U.S. Census $(2000,2010)$, the number of Asian Indians in Santa Clara County increased from 67,000 to 118,000 in 2000-2010, mirroring the $68 \%$ growth of the AI population in the rest of the state.

Many of the recent AI immigrants to Santa Clara County have entered the US through H1-B visas. This type of visa allows U.S. employers to sponsor qualified foreign nationals with specialized knowledge and skills. H-1B holders can come to the US to work in their field of expertise for three years, plus an additional optional three year extension. During these six years, the majority of H1-B holders successfully convert their immigration status to that of permanent residents, obtaining green cards for themselves and their families (Facchini, \& Lodigiani, 2014).

For a number of years, AIs have comprised more than $60 \%$ of the temporary skilled work force entering the United States. According to a 2012 U.S. Citizenship and Immigration Services report, 85,000 Indian-born workers were issued new three-year H-1B visas in 2012, while 82,000 Indian-born H-1B holders were granted three-year visa extensions. These numbers far exceed the statistics for the second- and the third-largest groups of $\mathrm{H}-1 \mathrm{~B}$ recipients: Chinese-born workers received 11,000 new and extended H-1B visas, and Canadian citizens received $8,000 \mathrm{H} 1-\mathrm{B}$ visas of both types. More than $50 \%$ of $\mathrm{H}-1 \mathrm{~B}$ visa holders from all countries $(155,000$ out of 263,000$)$ worked in computer-related occupations. Dell, Microsoft, Google, Nokia, and other high tech giants with large campuses in Silicon Valley have sponsored the largest numbers of H-1B visa holders from India (Chaudhuri, 2011; Sivakumar, 2004).

Kreisberg (2014) reported that there has been a significant gender disparity among H-1B visa recipients in technology-related fields: 78\% of $\mathrm{H}-1 \mathrm{~B}$ recipients are male, while $22 \%$ are female. An H1-B visa holder (usually a male) can 
sponsor his spouse to come to the US on an H-4 visa. This entails significant restrictions: $\mathrm{H}-4$ visa holders cannot obtain a social security number or secure employment within the United States (Kelkar, 2012). Many authors have reported on the difficulties faced by AI women joining husbands who have entered the United States on H1-B visas. These women - many of them educated professionals - struggle with a sense of isolation as they live in a foreign country, unable to work and separated from extended families and friends (Char, 2005; Ustinova, 2008; Sweas, 2012).

\section{Setting}

El Camino Hospital in Mountain View (ECH MV) is a 399-bed community hospital located in Santa Clara County, California. South Asian (predominantly AI) women account for approximately one third of all deliveries, outnumbering all other race-ethnic groups (El Camino Hospital Marketing and Communications [ECHMC], 2013). AI women had a higher rate of cesarean births (38\%) compared to Caucasian women (27\%). The episiotomy rate (i.e., the rate of surgical incisions of the perineum to facilitate delivery) was also noted to be higher among AI women having a vaginal birth (14\%), compared to Caucasian women having a vaginal birth (9\%). Although AI women represented only $17 \%$ of all vaginal births in the hospital, their share of third- and fourth-degree lacerations was 39\%. This suggests that AI women have an approximately $10 \%$ chance of third- or fourthdegree laceration in vaginal delivery, as opposed to a $2-3 \%$ chance for Caucasian women.

ECHMC (2013) conducted a patient satisfaction survey of maternity patients at ECH MV, consisting of three focus groups and one individual interview. The results suggested that AI women have more stress and anxiety 
associated with the process of childbirth, in addition to the higher incidence of physical complications described above. Another finding from the survey suggested that AI women's self-esteem may be more connected with the idea of having a natural childbirth (ECHMC, 2013). In this context, AI women often used the term "natural birth" to mean "vaginal birth," without necessarily meaning abstaining from labor induction or pain relief medication.

\section{Problem Statement}

During the last fifteen years, I have worked extensively with AI women at ECH MV. I have attended to the needs of AI women in the capacity of a certified nurse midwife and have provided prenatal, intrapartum, and postpartum care. Additionally, I have taught childbirth preparation classes, which include many AI couples who have received prenatal care from other providers in the community. As a result, I, along with my colleagues, have observed specific reproductive needs and challenges unique to AI women. Many of the issues I observedincluding difficulties with marriage consummation, lack of knowledge regarding reproductive anatomy, and an inability to tolerate pelvic exams- - have not been described in the literature. Therefore, the purpose of this study is to further explore reproductive HCPs' observations regarding specific challenges commonly experienced by AI women undergoing reproductive care. Moreover, it appears that providing care for AI women also brings certain challenges to the HCPs.

Therefore, the secondary goal of this study is to examine what HCPs perceive as especially challenging while taking care of AI women in a reproductive/perinatal setting.

Data from this study will help identify areas were there appears to be a mismatch between patients' and providers expectations regarding the healthcare 
process. The data will also improve HCPs' understanding of AI culture and thus enhance healthcare providers' ability to provide deliver culturally competent care. It can also serve as a basis for developing culturally competent patient education materials, as well as childbirth preparation classes specifically targeted towards AI women. 


\section{REPRODUCTIVE CHALLENGES OF ASIAN INDIAN WOMEN}

\section{CHAPTER 2: LITERATURE REVIEW}

This literature review will cover three areas.

1. Research that explores nurses' and midwives' experiences providing perinatal care to ECM women, with a focus on AI women.

2. Research that explores AI women's marital relationships and sexuality.

3. Research that explores the experiences of AI women during pregnancy, birth, and immediate postpartum recovery.

\section{Asian Indian Women: Experiences of Health Care}

\section{Providers}

To date, much of the research regarding HCP experience with AI women comes from industrialized countries other than United States. Cioffi (2004) interviewed 12 Australian midwives, all of whom had at least five years of experience. The study asked the following question: "How do experienced midwives care for women from culturally diverse backgrounds in an acute care setting?”(p. 437). Cioffi noted the lack of existing literature on the subject, but mentioned that previous studies of nurses in general healthcare settings found ECM patient care to be a source of unique difficulty and frustration for HCPs.

Cioffi found that midwives were very concerned with accommodating patients' cultural preferences, and considered it a main focus of caregiving. Midwives were eager to provide culturally competent care and educate themselves about the cultural preferences of their ECM clients. Possible accommodations included prolonged visitation hours and extra visitation space for patients whose culture demanded extensive hospital visits. However, none of the midwives mentioned culturally competent prenatal education for patients and families regarding the needs of a new mother for rest and sleep. Nobody discussed the 
concept of a compromise for situations when the patient's cultural beliefs did not align with the treatments midwives believed to be beneficial.

Vydellingum (2006) examined the experiences of 43 female and largely Caucasian (93\%) nursing staff members caring for South Asian patients in a general hospital in England. The sample included three ward sisters, 22 staff nurses, and 18 care assistants working in six different medical wards throughout the hospital. The study was conducted using focus group interviews with groups of 6-8 participants. Open-ended questions were used to guide the discussion. Analysis of interview data revealed eight general themes.

1. Changes in service in an attempt to accommodate the needs of the patients.

2. A false sense of equity.

3. Limited cultural knowledge.

4. Victim blaming.

5 . Valuing of relatives.

6. Denial of racism.

7. Ethnocentrism.

8. Self-disclosure.

The first two of the eight themes have especially broad relevance.

Healthcare facilities often respond to superficial differences in patient preferences (e.g. food preferences or type of religious worship) as if they were following a checklist, without properly understanding patients' underlying cultures. At the same time, HCPs often mistakenly assume they are acting fairly by "treating all patients the same." This approach ignores cultural differences and, while appearing superficially "fair," ends up subjecting minority patients to treatment that is designed for a "white" or "Western" paradigm. 
Vydelingum suggests that healthcare facilities perform cultural assessments of the staff in order to identify patterns that help or hinder nursing interventions. These assessments can guide the training of nurses in cultural competence. Vydelingum recommends the transformative cultural education model as a way to create an atmosphere of shared power between members of different but equal cultures. Future research can help to incorporate the suggestions of the HCP into patient teaching and preparation for the childbearing experience.

Reynolds and Shams (2005) explored how midwives $(\mathrm{n}=23)$ and student midwives $(n=7)$ in the UK perceive difficulties in providing effective prenatal care to women of South Asian origin. Participants ranged from 20-57 years of age and were mostly Caucasian (80\%), with a few South Asians (15\%). Participants were given six hypothetical pieces of information they might need to communicate to a patient of South Asian background during prenatal care, and were asked to rate the difficulty of conveying each piece of information. The respondents rated "information about reproductive choice after pregnancy" as the most challenging information to convey, followed by "reporting problems with pregnancy, e.g. Down's syndrome." The study focused solely on South Asian women; participants were not asked to compare the difficulty of discussions with South Asian women to discussions with women of other race-ethnic groups. The midwives identified language barriers and underestimation of the role of grandparents in the decisionmaking process as the major obstacles to prenatal care. They advocated for broader education on health promotion in the South Asian community, as well as closer ties between the community and healthcare professionals. 
REPRODUCTIVE CHALLENGES OF ASIAN INDIAN WOMEN

Asian Indian Women: Marital and Sexual

Relationships

Marriage and family life in India

Marriage in India is seen as, first and foremost, a union between two families, and not as means of individual self-fulfillment. The new bride is expected to join her husband's family, and the patrilineal joint family gives preference to the lineal relationship of parents and son over the conjugal relationship of husband and wife. The wife becomes fully integrated and achieves status in her new family once she becomes pregnant and produces a child, preferably a son (Uberoi, 2006). Traditionally elder female family members take on the responsibility of insuring that the pregnant woman eats well and rests often. Although the child-mother bond is considered strong in Indian culture, grandparents, aunts, uncles, and other members of the extended family take very active roles in children's upbringing; a mother-in-law or an older sister-in-law may perform a lot of infant care tasks (Kakar, 2009).

At the beginning of the $21^{\text {st }}$ century in India, $95 \%$ of women were married by the age of 25 , while $5 \%$ of women reported having sexual experience prior to marriage, less than $5 \%$ of women played a primary role in choosing their husband, and $78 \%$ knew their husband for one month or less by the time they got married (Desai \& Andrist, 2010). In an interview of 38 first-generation AIs living on the East Coast of the United States, all of them were found to have arranged marriages (Mehrotra \& Calasanti, 2010). Price (2011) interviewed 20 Asian Indian immigrants in Texas and found that, out of 19 married individuals, all but four had arranged marriages. This data shows that arranged marriages are still very prevalent in AI communities both inside and outside India. 
REPRODUCTIVE CHALLENGES OF ASIAN INDIAN WOMEN

Ranade (2011) presented a qualitative analysis of the first-year marital experiences of $26 \mathrm{AI}$ couples in arranged marriages. Of the 26 couples in her study, 15 were residing in India after their marriage and 11 were residing in the US; all participants in the study held at least a Bachelor's degree. Ranade observed that the transition into sexual intimacy tended to be abrupt in arranged marriages, as cultural rules and geographical distances prohibited individuals from experiencing sexual intimacy before marriage. Due to the taboo against talking about sex in Indian society little sex education occurs. Indian women often enter marriage without any knowledge about sexual anatomy and physiology and little preparation for the psychological aspects of entering a sexual relationship. Men have to rely on pornography and discussions with male friends to gather information about what to do during sex.

Male study participants in both Indian and U.S. samples were sensitive to the fact that their wives might be fearful of sex. They also showed an understanding of the fact that sex was not only about satisfying their needs, but also about making experience pleasurable for their wives. Couples in the study reported that the time it took them to achieve their first successful penetration ranged from approximately a day to a year and counting, with the average being between one and three months. Most participants reported that sexual activity was satisfying to them and contributed to feelings of closeness.

Female sexuality in India

Kakar \& Kakar (2007) suggest that discussion of sexuality is repressed in all strata of Indian society. They note that women in India commonly believe that fulfillment of the husband's sexual needs is an important marital obligation for a woman, but do not expect to enjoy the sexual relationship. Many educated women 
from upper castes do not even have words to discuss their genitals in their native language, and may refer to them using euphemisms as a "place of peeing." Kakars analyze the words that are used by Indian women to describe what is called "lovemaking" in English: "kaam"_-"work"; "dhandha"_-"business", "Aadmi bolna chahta bai"-_Man wants to speak", and "Hafte mein ek baar lagwa lete hain"- "I get done it to myself once a week." Kakars write:

With so many traditional women carrying the baggage of shame and guilt in relation to their (sexual) bodies, with all the images of insatiable women and the notion of sex being an act that drains man of power and vigor, running up in male cultural imagination, the omens for a joyful sexual life is the average Indian marriage is not promising. (p. 93).

Young women in India receive explicitly and implicitly negative messages about sexuality (Seervai, S., 2015). Trivedi (2014) related a complicated history of the attempts to introduce sex education for adolescents in India. The Indian government first discussed the question of sex education in 1993. In 2005, the government implemented the National Population Education Project in India's public schools, which focused on abstinence, faithfulness and condom usage. However, by April of 2007 some of the largest states in India, - including Maharashtra, Kerala, Karnataka, and Madhya Pradesh—banned sex education. Politicians declared sex education to be a Western evil that would ruin Indian society and prevent children from developing good character.

In 2009, the government introduced the Adolescent Education Programme, which mentioned sex primarily in the context of HIV prevention and abstinence. Publicity around gang rapes in India in the last couple of years renewed the national debate about sex education in schools. However, sex remains a completely taboo subject in most families, and the majority of the population 
believes that it is the woman's responsibility to behave in such a way that will not expose her to the risk of sexual assault (Suxton \& Kumar, 2013; Patel, 2013).

Research on female sexuality in India is scarce, and focuses mostly on "dysfunction." A study by Singh, Tharyan, Kekre, Singh, and Gopalakrishnan (2009) reported that $73 \%$ of 149 married women attending a clinic for unrelated medical issues met the criteria for female sexual dysfunction. Pain with intercourse was the least commonly reported problem, affecting "only" $64 \%$ of women, while more than $90 \%$ of women complained of difficulties with arousal and lubrication, and more than $85 \%$ reported difficulties with orgasm. Aggarwal et al. (2011) reported that $56 \%$ of 500 women surveyed met the criteria for sexual dysfunction, identifying age, menopausal status, low education levels, and chronic disease as the major risk factors. In contrast to previous studies, Varghese, Bansal, Kekre, and Jacob (2012) reported that only about one third of 150 women surveyed exhibited symptoms of sexual dysfunction. Comparing their results with results from previous studies, the authors stated that the differences were due to other researchers using "Western thresholds [sic]" to define dysfunction (p. 1773)

From these contradictory and confusing results, one can only conclude that researchers know very little about the sexuality of Indian women. The prevalence of sexual dysfunction appears to be high, but the cultural taboos around sex, lack of sex education, and lack of general knowledge about human sexuality makes the true situation difficult to assess.

Sexuality of AI Women in the US

To date, only Fisher, Bowman, and Thomas (2002) have described sexual and reproductive challenges among AI women in the United States. They addressed the topic in two case studies. The first case study followed a 37-year-old 
professional AI female undergoing infertility evaluation after nine years of marriage. A physical exam determined that the marriage had not yet been consummated. In the second case study, researchers questioned a 25 -year-old college-educated AI female who denied "having sex," but admitted that her boyfriend was doing "something down there." The authors note that Indian culture regards sex as a duty that is not supposed to be pleasurable for women. The authors suggest that lack of consummation may be an issue among couples in arranged marriages.

\section{Asian Indian Women: Pregnancy, Birth, and Breastfeeding}

Pregnancy, Birth, and Breastfeeding

in India

In India, women's access to perinatal services differs drastically between urban and rural areas. The National Family Health Survey found that only $51 \%$ of rural population received three or more prenatal visits during pregnancy in 20052006, and only $40 \%$ delivered their babies in the hospital (Vora et al., 2009). The same survey found that cesarean rates averaged $6 \%$ in rural areas and $18 \%$ in urban areas, with a national rate of $10 \%$, in 2005-2006. Although literature continues to cite these statistics (Ghosh, 2010), the numbers are changing rapidly in both rural and urban areas of India.

As in many other developing countries, the rate of operative births is rising dramatically in India, as is the overuse of medical technology in general. In a rural medical college in the state of Haryana, cesarean section rates increased from $31 \%$ to 51\% during the period between 2007 and 2012 (Singh \& Gupta, 2013). More recently, Nagpal et al. (2015) conducted a population-based cluster randomized household survey, investigating perinatal experiences of women who had babies 
within a six-month period in Delhi, one of the largest metropolitan centers in India. The results were reported for three different socioeconomic groups. For the women in the highest socioeconomic group, more than $97 \%$ delivered babies in hospitals; more than $80 \%$ of these deliveries took place in private hospitals. Of the women in this group who delivered in private hospitals, more than $99 \%$ received more than three prenatal visits, and more than $87 \%$ received four or more ultrasound scans during pregnancy. The data for this high socioeconomic class (HSEC) is particularly relevant to my study, because these women match the socioeconomic profile of most female immigrants to the Silicon Valley from India.

Only $2 \%$ of HSEC women delivering in private hospitals were asked about physical or mental abuse or feeling of sadness during pregnancy; $44 \%$ were told about preterm labor and $27 \%$ received information about labor analgesia. Cesarean section rate was $41 \%$ for in smaller private hospitals or "nursing homes" (less than 25 beds) and 54\% for women in larger private hospitals. Labor support was provided for $15 \%$ of women in larger private hospitals $(77 \%$ of the time by the husband and $23 \%$ of the time by other relatives), and for $5 \%$ of patients in nursing homes ( $50 \%$ of the time by the husband, and $50 \%$ of the time by other relatives). More than $70 \%$ of HSEC women received routine episiotomies, and more than $50 \%$ received enemas. While less than $8 \%$ of women delivering in the private hospitals received epidurals, more than $40 \%$ were not allowed to move during labor or take oral fluids. Less than $1 \%$ of women delivered in non-supine positions, and less than $30 \%$ of women who delivered in private hospitals were allowed to touch the baby within 30 minutes after the birth. Initiation of breastfeeding within 24 hours happened in $52 \%$ of larger private hospitals and in $64 \%$ of nursing homes; formula or animal milk was given within 48 hours to $45 \%$ of babies born in larger private hospitals, and to $35 \%$ of babies born in nursing 
homes. The rates of discarding colostrum for larger hospitals and smaller nursing homes were $8.2 \%$ and $11.9 \%$ respectively.

These studies from India show evidence of fast medicalization of pregnancy and birth. However, while western technologies such as ultrasounds and cesarean sections have become very popular, India has generally not adopted western reproductive concepts such as prenatal education, labor support, and the importance of skin-to-skin newborn care and exclusive breastfeeding.

\section{Pregnancy, Birth, and Breastfeeding} among AI Immigrants

Few studies have looked at the pregnancy, labor and birth experiences of immigrant AI women in North America. Brar et al. (2009) showed that South Asian women in Canada do not use prenatal services as much as their Canadianborn counterparts; in this study, healthcare providers also recommended fewer prenatal classes to South Asian patients. South Asian patients cited husbands' unwillingness as a reason for not attending classes, and reported a preference for acquiring prenatal knowledge from female relatives and friends.

Ladha (2010) interviewed ten South Asian women, all of whom had immigrated to Canada during the previous ten years, about their prenatal experience. The women in this study understood the importance of staying physically and emotionally healthy during pregnancy, but reported that they did not receive enough information about their healthcare options from providers. Only one of the ten women interviewed had attended childbirth preparation classes. The others did not know about the classes, did not want to pay for the classes, or did not want to attend the classes if their partners could not accompany them. Instead, these women preferred to get information from friends, older family members, the internet, and books. 
Spitzer (2007) found that some South Asian Canadian women did not participate in community prenatal classes due to a language barrier. Others believed that childbirth processes should not be discussed with others until the time of birth. Some authors claim that South Asian women are less likely to seek prenatal care services than their North American-born counterparts because they view pregnancy as a normal life process, rather an illness requiring medical attention (Hoskins, 2004; Assanand et al., 2005).

A systematic review and meta-analysis of cesarean births in international migrants (Merry, Small, Blondel, \& Gagnon, 2013) found that South Asian immigrant women have consistently higher cesarean section rates for both primigravidas and multigravidas compared to non-immigrant women. The most commonly reported risk factors for cesarean section for immigrant women were (in order of frequency): language/communication barriers, low social economic status, poor maternal health (e.g., anemia, STIs, TB, parasitic infections), gestational diabetes/high body mass index, feto-pelvic disproportion, and lack of prenatal care. Most of these factors do not seem to apply to the AI population of Silicon Valley, who tend to be healthy, speak fluent English, and have high socioeconomic status. AI women in Silicon Valley also tend to start prenatal care early in the pregnancy, and have frequent prenatal appointments.

Wong et al. (2008) analyzed data from 2003 birth certificates to investigate the difference in perinatal outcomes between different Asian subgroups. A total of 202,686 non-Hispanic Asian women were eligible for this study. This study showed that AI women had the greatest incidence of primary cesarean delivery (21.2\%), diabetes (8.1\%), and birth weight less than $2500 \mathrm{~g}(4.8 \%)$. Rao, Daniels, El-Sayed, Moshesh, \& Caughey (2006) conducted a retrospective study using the data from deliveries in Stanford hospital in California between 1998 and 2003. 
The study showed that AI ethnicity was a risk factor for gestational diabetes, preterm delivery, and low birth weight, but cesarean section rates among AI women were just slightly higher than average: $23.7 \%$ for AI women, as opposed to $22.6 \%$ for all Asian women.

Many studies have shown a high incidence of severe perineal trauma in Asian women giving vaginal birth in Western countries, relative to Caucasian women. Unfortunately, very few of the studies looked specifically at the AI population. Hopkins, Caughey, Glidden, \& Laros (2005) analyzed records from the UCSF perinatal database from 1976 to 2001. The study separated Asian ethnicities into Chinese, Japanese, Filipina and "other Asian," which consisted predominantly of Southeast Asians, Asian Indians, and Pacific Islanders. As a whole, the Asian ethnicity, including "other Asian," was shown to be a risk factor for perineal lacerations. Handa, Danielsen, \& Gilbert, (2001) examined obstetric anal sphincter lacerations (used interchangeably with third- and fourth-degree lacerations and severe perineal lacerations) in a retrospective study of more than 2 million vaginal deliveries at California hospitals, using information from birth certificates and discharge summaries for 1992 through 1997. Indian ethnicity was associated with the highest chance of severe perineal lacerations (OR 2.50; 95\% CI 2.23, 2.79) compared to Caucasians.

Literature suggests that breastfeeding well beyond the child's first birthday is a cultural norm in many traditional societies. Cowin (1999) interviewed Asian Indian new mothers and Asian Indian healthcare providers residing in Canada regarding breastfeeding experiences and decision-making influences. The study found that, despite Asian Indian women's preference for exclusive and prolonged breastfeeding, most mothers accepted early introduction of breast milk substitutes. The reasons cited for this included the desire to resume gainful employment, 
satisfaction with the baby, and the impression that this was what women did in Canada. Studies from Great Britain and Australia support the hypothesis that women with higher acculturation levels are less likely to breastfeed their babies exclusively, and are more likely to introduce breast milk substitutes. Less acculturated mothers believe strongly in the traditional importance and health benefits of breastfeeding, while more acculturated mothers are more likely to be influenced by the examples of their Western counterparts (Choudhry \& Wallace, 2012; Maharaj \& Bandyopadhyay, 2013).

In a U.S. study, Asian Indian mothers breastfed for shorter periods than Anglo-American mothers, and were more likely to ask extended family members for breastfeeding advice instead of seeking guidance from health professionals (Kannan, Carruth, \& Skinner, 1999). Nagpal, et.al (2015) found that more than one third of babies born in private hospitals in New Delhi received a breast milk substitute within 48 hours of birth, so the preference for prolonged and exclusive breastfeeding might not hold true for India's current population.

Although I've found a considerable gap in literature describing U.S. HCPs' experiences with AI women's reproductive care, the findings from other countries suggest that communication barriers and HCPs' ignorance of cultural expectations and needs might be obstacles to care. The literature suggests that AI women in Silicon Valley reproductive healthcare facilities may have come to the United States to join their husbands in arranged marriage; they may have grown up expecting to become a part of their future husband's extended family and to rely on family members for help caring for children. These women may have had little or no education about human sexuality and reproduction, and may have received contradictory messages about what normal birth involves. AI immigrant women in 
Silicon Valley also experience a number of profound transitions, which I will discuss in the next section.

\section{Theoretical Framework}

Afaf Meleis extensively studied the process of immigrant assimilation into a new culture, which she described in the context of transitions theory (Meleis, Sawyer, Im, Hilfinger Messias, \& Schumacher, 2000). Out of the five studies used to provide empirical data for the concepts of transitions theory, three featured populations similar to the population of interest in this study-Korean middleaged women, African American mothers, and Brazilian female immigrants (Im, 2009).

There are several different transitions that might affect AI women coming to Silicon Valley. First, these women are getting married - a process that entails a developmental transition from a maiden to a sexually active woman, as well as a situational transition, from a daughter living at home with parents to a wife living with a husband. Upon marrying a husband and joining him in the United States, AI immigrant women become geographically isolated from their natal families and friends, and dependent on men they barely know. Culturally, these women expect to become a part of a large extended family and to rely on the husband's female family members for emotional and physical support. This does not happen when a woman marries a man who has come to the United States alone for work or study. Researchers have not yet studied the effects of transitioning into marriage and parenthood while undergoing the transitions of immigration, as experienced by AI women coming to Silicon Valley.

Furthermore, AI women coming to Silicon Valley are experiencing the situation transition of migrating to another country. Because some of them may be 
planning to return home some time in the future, they end up in a "no man's land"- a permanent transition state, as there is no defined end point to this transition.

Finally, like their counterparts at home, AI women immigrating to Silicon Valley experience the organizational transition inherent in living at a time when traditional Indian family values are undergoing significant changes due to globalization, industrialization, and information exchange. According to Meleis (2010) focusing on transitions allows the simultaneous use of different theories from other disciplines, such as psychoanalysis and postcolonial feminism, to understand the experiences of the population of interest. 


\section{REPRODUCTIVE CHALLENGES OF ASIAN INDIAN WOMEN}

\section{CHAPTER 3: METHODOLOGY}

\section{Design}

A quantitative, cross-sectional, descriptive design was used for the proposed study.

\section{Sample and Setting}

I invited a convenience sample of healthcare professionals practicing in Santa Clara County to participate in this study. The participants were over 18 years of age, able to read and write English, and were involved in the care of childbearing AI women. The sample included registered nurses, OB/GYN physicians, midwives, lactation consultants, primary care physicians and one advanced practice nurse employed in primary care. The primary setting for this study was El Camino Hospital (ECH), a community hospital in Santa Clara County, California. ECH has two campuses: the campus in Mountain View (ECH MV) is licensed for 399 beds, 88 of which are designated for maternal-child health; the Los Gatos campus (ECH LG) is licensed for 180 beds, 20 of which are designated for maternal-child health. Overall, ECH MV averages approximately 350 deliveries per month, and ECH LG averages approximately 70 deliveries per month.

\section{Measures}

Health Care Professionals' perceptions of the reproductive challenges and experiences of AI women were assessed with a 71-item investigator-developed survey. I created the questions in the survey based on the studies discussed in the literature review sections. I conducted multiple informal focus groups with reproductive HCPs taking care of $\mathrm{AI}$ women at $\mathrm{ECH} \mathrm{MV}$, in order to reflect their observations and experiences specific to the U.S., and particularly Silicon Valley. 
In this way, I hoped to the current gap in literature about the reproductive/perinatal experiences of AI women in the United States.

The survey included six sections. The first section consisted of six demographic questions, including questions about respondents' occupation, age, and ethnicity. The second section consisted of six questions about respondents' general impressions of their AI clients and their needs. The next four sections used Likert-type scales. These four sections included 11 questions about patient marital relationships and contraception use, 12 questions about patients' prenatal periods, 20 questions about labor and birth, and 13 questions about patient postpartum recovery in the hospital. These questions assessed how often AI women experienced certain reproductive challenges, compared to women from other raceethnic groups. Participants could skip the areas that did not pertain to their practice. Four open-ended questions allowed participants to give narrative answers. At the end of the survey, participants had the opportunity to provide any additional information about their experience caring for AI women.

\section{Data Collection Procedure}

After obtaining approval from ECH and CSU Fresno International Review Boards, I distributed the link to the survey through email, on-line announcements, and personal communications. The link to the survey was accompanied by a cover letter informing participants of the purpose of the research and assuring them of the confidentiality of all provided information. Participants were given contact information in case they had any questions regarding the research (Appendix A). No participant self-identifying data was collected.

In order to maintain anonymity, the link to the survey was emailed to 103 labor and delivery (L\&D) nurses and 122 mother-baby unit (MBU) nurses on the 
ECH Mountain View campus, as well as $25 \mathrm{~L} \& \mathrm{D}$ and $14 \mathrm{MBU}$ nurses on the ECH Los Gatos campus. The link was sent by the units' nurse-managers. The survey was introduced to $\mathrm{OB} / \mathrm{GYN}$ physicians on the Mountain View campus during the November department meeting. The link to the survey was emailed by the medical director of the OB department of Palo Alto Medical Foundation to OB/GYN physician-members who have delivery privileges in ECH MV. Flyers were distributed in L\&D and MBU at ECH MV and ECH LG. I sent emails with links to the survey to HCPs in Santa Clara County whom I knew personally. The survey was available on-line to all reproductive health professionals in Santa Clara County from mid-November 2014 to mid-January 2015.

\section{Data Analysis}

Participant demographic data and characteristics was analyzed using descriptive statistics, including frequencies, means, and measures of central tendencies.

\section{$\underline{\text { Research question } 1}$}

What is the general perception of the AI female population in Silicon Valley by women's health care providers? I used descriptive frequencies, means, and measures of central tendencies to analyze HCPs perceptions of AI female patient characteristics. I analyzed the prevalence of AI women in providers' practices, providers' perceptions of AI patients' oral English language proficiency, providers' perceptions of AI patients education levels, as well as providers' perceptions of the prevalence of long-distance marriages into America among their AI patients. 
Research question 2:

What do reproductive HCP observe as specific challenges commonly experienced by AI women? I used descriptive frequencies in EXCEL Version 14.4 for Mac 2011 to analyze respondents' answers to Likert scale questions. I synthesized participants' answers to open-ended question and comments and extracted common themes.

Research question 3

What do HCPs perceive as especially challenging while taking care of AI women in reproductive/perinatal settings? I used descriptive frequencies in EXCEL Version 14.4 for Mac 2011 to analyze respondents' answers to Likert scale questions. I synthesized participants' answers to open-ended question and comments and extracted common themes. 


\section{REPRODUCTIVE CHALLENGES OF ASIAN INDIAN WOMEN}

\section{CHAPTER 4: RESULTS}

\section{Participant Characteristics}

A convenience sample of 76 professionals participated in the study. Of these, the majority reported being between 30 and 50 years of age $(n=51,67 \%)$, female $(\mathrm{n}=68,89 \%)$, and Caucasian $(\mathrm{n}=42,55 \%)$. More than half of participants ( $\mathrm{n}=46,61 \%$ ) identified as L\&D or MBU nurses. The majority of respondents were affiliated with El Camino Hospital $(n=65,86 \%)$. Between the two ECH campuses, most respondents were affiliated with the larger Mountain View campus $(n=57$, $74 \%$ ), whereas nine respondents (12\%) were affiliated with the Los Gatos campus. The rest of the respondents $(\mathrm{n}=9,12 \%)$ were affiliated with Good Samaritan Hospital, Santa Clara County Valley Medical Center, Kaiser Permanente, Alameda County System, and Highland Hospital. Please see Table 1 for more complete data.

Table 1: Sample Characteristics $(\mathrm{N}=76)$

\begin{tabular}{|l|l|}
\hline Characteristics & $\mathrm{N}(\%)$ \\
\hline Age (in years) & \\
\hline$<30$ & $3(4 \%)$ \\
\hline $30-50$ & $51(67 \%)$ \\
\hline$>50$ & $19(25 \%)$ \\
\hline Decline to answer & $3(4 \%)$ \\
\hline Gender & \\
\hline Male & $6(8 \%)$ \\
\hline Female & $68(89 \%)$ \\
\hline Decline & $2(3 \%)$ \\
\hline Race-ethnicity & \\
\hline
\end{tabular}




\begin{tabular}{|c|c|}
\hline Caucasian & $42(55 \%)$ \\
\hline Asian Indian & $6(8 \%)$ \\
\hline $\begin{array}{l}\text { Other Asian (Filipino, Chinese, Japanese, } \\
\text { Korean, "other Asian") }\end{array}$ & $12(16 \%)$ \\
\hline Native American & $2(3 \%)$ \\
\hline Latino & $5(7 \%)$ \\
\hline African American & $1(1 \%)$ \\
\hline Decline to answer & $8(10 \%)$ \\
\hline \multicolumn{2}{|l|}{ Professional Role } \\
\hline Primary care provider physician & $5(7 \%)$ \\
\hline Advanced practice nurse & $1(1 \%)$ \\
\hline Obstetrician-Gynecologist & $16(21 \%)$ \\
\hline Certified nurse midwife & $5(7 \%)$ \\
\hline Labor and delivery nurse & $18(24 \%)$ \\
\hline Mother-baby nurse & $26(34 \%)$ \\
\hline Lactation consultant & $3(4 \%)$ \\
\hline NICU nurse (answered IP questions) & $1(1 \%)$ \\
\hline Decline to answer (answered IP questions) & $1(1 \%)$ \\
\hline \multicolumn{2}{|l|}{ Hospital Affiliation } \\
\hline El Camino Hospital - Mountain View & $57(75 \%)$ \\
\hline El Camino Hospital - Los Gatos & $9(12 \%)$ \\
\hline $\begin{array}{l}\text { Other (Good Samaritan, Kaiser, SCVMC, } \\
\text { Alameda County System, Highland) }\end{array}$ & $8(11 \%)$ \\
\hline Outpatient only & $1(1 \%)$ \\
\hline Declined to answer & $1(1 \%)$ \\
\hline
\end{tabular}


The prevalence of AI female patients varied significantly among respondents. The majority of respondents reported that more than $30 \%$ of their patients were of Asian Indian descent $(\mathrm{n}=54,68 \%)$. Among respondents associated with ECH MV, the amount of providers who reported AI patient rates of more than $30 \%$ was even higher $(n=48,84 \%)$. Please see Table 2 for complete data.

Table 2. Percentage of AI Patients in Respondents' Practice

\begin{tabular}{|c|c|c|c|c|c|c|c|c|}
\hline & Total & $<11 \%$ & $\begin{array}{l}11 \%- \\
30 \%\end{array}$ & $31 \%-50 \%$ & $\begin{array}{l}51 \%- \\
70 \%\end{array}$ & $\begin{array}{l}71 \%- \\
90 \%\end{array}$ & $>90 \%$ & Blank \\
\hline All & 76 & 3 & 18 & 19 & 24 & 8 & 3 & 1 \\
\hline $\begin{array}{l}\mathrm{ECH} \\
(\mathrm{MV})\end{array}$ & 57 & 0 & 8 & 15 & 23 & 7 & 3 & 1 \\
\hline
\end{tabular}

Research Question 1: Description of AI Patients in Silicon Valley

Three questions in the survey were geared towards description of AI female patients:

Ability to Verbally Communicate in

English.

Sixty-two (82\%) of all participants described patients' ability to communicate verbally in English as "fluent" or "very fluent" (4 or 5 on a $0-5$ scale). In the narrative section of the survey, only five out of 76 respondents (7\%) mentioned language as a barrier. 
Provider's Perception of Patients'

Education Level.

Fifty-five participants (79\%) believed that more than $50 \%$ of their patients had college-level educations or above. Forty-three participants (53\%) believed that more than $75 \%$ of their patients had college-level educations or above.

Perceptions of Frequency of "Long Distance" Marriages to AI Men in the United States.

I asked respondents to estimate the percentage of their AI female patients who came to the United States after marrying an AI man who was already living there. Out of 76 respondents, $48(63 \%)$ answered this question. The majority $(\mathrm{n}=28,58 \%)$ estimated that more than $50 \%$ of their patients came to the United States after marrying an AI man who was already livining the United States. I also performed a separate analysis on the responses of $\mathrm{OB} / \mathrm{GYNs}$ practicing in $\mathrm{ECH}$ MV. I anticipated that this group of respondents, which has the most AI patients and care for them for the duration of pregnancy, would have the most opportunities to get to know them better. Indeed, 11 out of 12 ECH MV OB/GYNs (92\%) answered the question. Seven of the 11 of ECH MV OB/GYNs (64\%) estimated that more than $50 \%$ of their patients came to US after marrying an AI man who was already living here.

Research Question 2: Prevalence of Certain Challenges and Experiences in AI Women Compared to Women from Other Race-Ethnic Groups

Four sections of the survey explore providers' perceptions of the prevalence of certain healthcare challenges facing AI women. In these sections all questions presented the respondent with a Likert scale from 1 to 5 , with 1 representing a situation that "occurs significantly less often" and 5 representing a situation that "occurs significantly more often." The respondents were asked to rate the 
healthcare issues based on whether they occur more or less frequently among their AI female patients, compared to female patients from other race-ethnic groups.

These four sections addressed: sexual health, pelvic exams and contraception use (GYN care), the prenatal period (AP care), labor and birth (IP care), and the immediate postpartum period (PP care). Depending on the respondents' scope of practice and current employment, they answered corresponding sections of the survey (see Table 3 ). The response rate generally matched my expectations, except that more respondents than expected answered questions on postpartum care, which were mostly intended for Mother Baby Unit (MBU) nurses and Lactation Consultants (LC). One ECH LG NICU nurse answered the questions on IP care, so I assumed that she might sometimes float to Labor and Delivery and take care of patients in labor.

Table 3. Distribution of Answers to Four Sections by Professional Role.

\begin{tabular}{|l|l|l|l|l|l|}
\hline Professional role & Total & GYN care & AP care & IP care & PP care \\
\hline PCP & 5 & 5 & & & 1 \\
\hline APN & 1 & 1 & & & 0 \\
\hline OB/GYN & 16 & 16 & 16 & 16 & 11 \\
\hline CNM & 5 & 5 & 5 & 3 & 4 \\
\hline LD/NICU nurse & 20 & & & 20 & 8 \\
\hline MBU nurse & 26 & & & & 24 \\
\hline LC & 3 & & & & 3 \\
\hline Agreed to & 76 & 27 & 21 & 39 & 51 \\
answer & & & & & \\
\hline
\end{tabular}


The answers to these questions were analyzed for frequencies and compiled into categories of "more often" (numbers 4 and 5 on the scale) and "less often" (numbers 1 and 2 on the scale). These results were combined with narrative answers to four open-ended questions. The open-ended questions asked respondents to describe what they perceived to be the most common reproductive challenges of AI women; what they, as healthcare providers, perceived to be their personal greatest challenges when caring for AI women; what were their greatest obstacles to establishing therapeutic relationships with AI women; and suggestions for improving the experiences of AI women receiving reproductive care system in Silicon Valley.

Five areas were identified as especially challenging for Asian Indian women seeking reproductive services in Silicon Valley. Table 4 summarizes the compiled answers applicable to each of five areas in more details.

Table 4. Most Significant Trends in Reproductive Experiences of Asian Indian Women

\begin{tabular}{|l|l|l|}
\hline Question & $\begin{array}{l}\text { Answered "more often" } \\
\text { or "significantly more } \\
\text { often" }\end{array}$ & $\begin{array}{l}\text { Answered "less often" } \\
\text { or "significantly less } \\
\text { often" }\end{array}$ \\
\hline Difficulty with relaxing pelvic area, as evident by problems with intercourse \\
and difficulty in tolerating pelvic exams. \\
\hline $\begin{array}{l}\text { Unconsummated } \\
\text { marriage }\end{array}$ & $71 \%$ & $7 \%$ \\
\hline $\begin{array}{l}\text { Difficulty achieving } \\
\text { penetration during } \\
\text { intercourse }\end{array}$ & $86 \%$ & $3 \%$ \\
\hline
\end{tabular}




\begin{tabular}{|c|c|c|}
\hline Pain during intercourse & $79 \%$ & $0 \%$ \\
\hline Avoidance of intercourse & $81 \%$ & $0 \%$ \\
\hline $\begin{array}{l}\text { Unable to undergo pelvic } \\
\text { and/or speculum exam (in } \\
\text { the office) }\end{array}$ & $87 \%$ & $0 \%$ \\
\hline $\begin{array}{l}\text { Report or appear to } \\
\text { experience pain (more } \\
\text { than expected discomfort) } \\
\text { during pelvic and/or } \\
\text { speculum exam }\end{array}$ & $87 \%$ & $0 \%$ \\
\hline $\begin{array}{l}\text { Experience difficulty } \\
\text { tolerating pelvic exams } \\
\text { during labor }\end{array}$ & $93 \%$ & $0 \%$ \\
\hline \multicolumn{3}{|c|}{$\begin{array}{l}\text { Lack of health education and knowledge, increased anxiety and self-doubt, } \\
\text { but reluctance to enroll in classes or prepare a birth plan. }\end{array}$} \\
\hline $\begin{array}{l}\text { Lack of knowledge } \\
\text { regarding human } \\
\text { sexuality and } \\
\text { reproductive anatomy }\end{array}$ & $78 \%$ & $0 \%$ \\
\hline $\begin{array}{l}\text { Appear exceedingly } \\
\text { anxious about pregnancy }\end{array}$ & $63 \%$ & $13 \%$ \\
\hline $\begin{array}{l}\text { Have excessive anxiety } \\
\text { about upcoming birth } \\
\text { (during pregnancy) }\end{array}$ & $61 \%$ & $4 \%$ \\
\hline
\end{tabular}




\begin{tabular}{|l|l|l|}
\hline $\begin{array}{l}\text { Are more likely to use } \\
\text { after hours answering } \\
\text { services (during } \\
\text { pregnancy) }\end{array}$ & $61 \%$ & $4 \%$ \\
\hline $\begin{array}{l}\text { Attend childbirth } \\
\text { preparation classes }\end{array}$ & $35 \%$ & $17 \%$ \\
\hline $\begin{array}{l}\text { Attend breastfeeding } \\
\text { preparation classes }\end{array}$ & $25 \%$ & $29 \%$ \\
\hline $\begin{array}{l}\text { Have specific preference } \\
\text { for labor and create a } \\
\text { birth plan }\end{array}$ & $9 \%$ & $43 \%$ \\
\hline $\begin{array}{l}\text { Husband/partner has } \\
\text { multiple questions and } \\
\text { concerns regarding } \\
\text { pregnancy }\end{array}$ & $91 \%$ & $0 \%$ \\
\hline $\begin{array}{l}\text { Appear excessively } \\
\text { anxious about labor (in } \\
\text { labor) }\end{array}$ & $78 \%$ & $3 \%$ \\
\hline $\begin{array}{l}\text { Tend to arrive in the } \\
\text { hospital before active } \\
\text { labor is established }\end{array}$ & $75 \%$ & \\
\hline $\begin{array}{l}\text { Are less likely to have } \\
\text { attended childbirth } \\
\text { preparation or } \\
\text { breastfeeding classes (in } \\
\text { labor) }\end{array}$ & $45 \%$ & \\
\hline
\end{tabular}




\begin{tabular}{|c|c|c|}
\hline $\begin{array}{l}\text { Appear to have little } \\
\text { knowledge and unrealistic } \\
\text { expectations of labor }\end{array}$ & $67 \%$ & $8 \%$ \\
\hline $\begin{array}{l}\text { Appear reluctant to take } \\
\text { care of self (postpartum) }\end{array}$ & $76 \%$ & $3 \%$ \\
\hline $\begin{array}{l}\text { Show increase anxiety } \\
\text { regarding ability to } \\
\text { breastfeed }\end{array}$ & $68 \%$ & $3 \%$ \\
\hline $\begin{array}{l}\text { Appear reluctant to take } \\
\text { care of baby and ask staff } \\
\text { to perform baby care }\end{array}$ & $83 \%$ & $3 \%$ \\
\hline \multicolumn{3}{|c|}{$\begin{array}{l}\text { Heavy reliance on and delegation of decision making to husband and/ or } \\
\text { family members, but possibly lack of control over involvement of family } \\
\text { members. }\end{array}$} \\
\hline $\begin{array}{l}\text { Husband/partner } \\
\text { accompanies patient to } \\
\text { most appointments }\end{array}$ & $83 \%$ & $0 \%$ \\
\hline $\begin{array}{l}\text { Husband/partner has } \\
\text { multiple questions and } \\
\text { concerns regarding } \\
\text { pregnancy }\end{array}$ & $91 \%$ & $0 \%$ \\
\hline $\begin{array}{l}\text { Expect/allow } \\
\text { husband/partner to } \\
\text { answer questions } \\
\text { addressed to the patient, }\end{array}$ & $87 \%$ & $3 \%$ \\
\hline
\end{tabular}




\begin{tabular}{|l|l|l|}
\hline $\begin{array}{l}\text { including personal } \\
\text { questions (in labor) }\end{array}$ & \\
\hline $\begin{array}{l}\text { Defer to husband/partner } \\
\text { for making decisions } \\
\text { regarding her own care } \\
\text { (in labor) }\end{array}$ & $88 \%$ & $3 \%$ \\
\hline $\begin{array}{l}\text { Extended family } \\
\text { members provides hands } \\
\text { on support to laboring } \\
\text { woman }\end{array}$ & $56 \%$ & $3 \%$ \\
\hline $\begin{array}{l}\text { Extended family } \\
\text { members are likely to be } \\
\text { present in the room } \\
\text { during pushing }\end{array}$ & $55 \%$ & $3 \%$ \\
\hline $\begin{array}{l}\text { Defer to family for } \\
\text { making decisions } \\
\text { regarding her own care } \\
\text { (postpartum) }\end{array}$ & $83 \%$ & $3 \%$ \\
\hline $\begin{array}{l}\text { Defer to family for } \\
\text { making decisions } \\
\text { regarding baby care }\end{array}$ & $75 \%$ & $3 \%$ \\
\hline $\begin{array}{l}\text { Plan to rely on family } \\
\text { members for the care of } \\
\text { the baby } \\
\text { home at the time of }\end{array}$ & $87 \%$ & \\
\hline
\end{tabular}




\begin{tabular}{|c|c|c|}
\hline discharge & & \\
\hline $\begin{array}{l}\text { Ask staff for help in } \\
\text { managing extended } \\
\text { family }\end{array}$ & $47 \%$ & $3 \%$ \\
\hline \multicolumn{3}{|c|}{$\begin{array}{l}\text { Extra challenges in working with pain and physical demands of labor and } \\
\text { childbirth recovery }\end{array}$} \\
\hline $\begin{array}{l}\text { Perceive early labor as } \\
\text { extremely painful }\end{array}$ & $75 \%$ & $3 \%$ \\
\hline $\begin{array}{l}\text { Are having hard time } \\
\text { following directions } \\
\text { during labor }\end{array}$ & $64 \%$ & $3 \%$ \\
\hline $\begin{array}{l}\text { Have hard time } \\
\text { coordinating pushing } \\
\text { efforts }\end{array}$ & $79 \%$ & $3 \%$ \\
\hline $\begin{array}{l}\text { Have a cesarean section } \\
\text { in pushing stage due to } \\
\text { lack of fetal descent }\end{array}$ & $64 \%$ & $0 \%$ \\
\hline $\begin{array}{l}\text { Have high rate of } \\
\text { operative vaginal } \\
\text { deliveries (forceps, } \\
\text { vacuum extractors) }\end{array}$ & $61 \%$ & $3 \%$ \\
\hline $\begin{array}{l}\text { Have many complaints } \\
\text { regarding physical } \\
\text { discomforts (postpartum) }\end{array}$ & $78 \%$ & $3 \%$ \\
\hline \multicolumn{3}{|c|}{ Lack of understanding of role of nurses in American healthcare and possibly } \\
\hline
\end{tabular}




\begin{tabular}{|l|l|l|}
\hline \multicolumn{2}{|l|}{ lack of trust of nurses. } & \multicolumn{2}{l|}{$5 \%$} \\
\hline $\begin{array}{l}\text { Give impression that they } \\
\text { do not trust nurses (in } \\
\text { labor) }\end{array}$ & $59 \%$ & $2 \%$ \\
\hline $\begin{array}{l}\text { Give impression that they } \\
\text { do not understand the role } \\
\text { of nurses in the hospital } \\
\text { (in labor) }\end{array}$ & $68 \%$ & $0 \%$ \\
\hline $\begin{array}{l}\text { Tend to ask the same } \\
\text { question many times (in } \\
\text { labor) }\end{array}$ & $88 \%$ & $3 \%$ \\
\hline $\begin{array}{l}\text { Extended family } \\
\text { members give impression } \\
\text { that they do not trust } \\
\text { nurses and second-guess } \\
\text { their advice. (in labor) }\end{array}$ & $69 \%$ & $3 \%$ \\
\hline $\begin{array}{l}\text { Tend to ask the same } \\
\text { question many times (in } \\
\text { postpartum) }\end{array}$ & $87 \%$ & \\
\hline
\end{tabular}

Difficulty with Relaxing Pelvic Area

Respondents to the GYN section felt that AI women were more likely that women from other race-ethnic groups to experience unconsummated marriage (71\%), difficulty achieving penetration (86\%), pain during intercourse (79\%), and avoidance of intercourse (71\%). AI women were also reported to have significant 
trouble tolerating pelvic exams both in the office $(87 \%)$ and in the hospital during labor $(93 \%)$.

In response to open-ended questions about AI women's typical reproductive health issues, OB/GYNs most commonly mentioned vaginismus, dyspareunia, and inability to tolerate pelvic exams. Meanwhile, almost $50 \%$ of labor and delivery nurses mentioned anxiety, tension and pain during vaginal exams in their answers to this question.

\section{Lack of Health Education and}

Knowledge

Seventy-nine percent of respondents to the GYN section observed a lack of knowledge of human sexuality and reproductive anatomy among AI women, compared to women of other race-ethnic groups. HCPs perceived AI women as being excessively anxious about pregnancy and labor while pregnant (63\% and $61 \%$ of respondents reported excessive anxiety about pregnancy and labor respectively). Even more HCPs perceived AI women as excessively anxious during the labor itself ( $78 \%$ of respondents reported excessive anxiety in AI women compared to other race-ethnic groups).

Ninety-one percent of AP section respondents reported that AI women's husbands/partners are more likely to have multiple questions and concerns about pregnancy. Sixty-seven percent of IP section respondents noted that AI women were more likely to lack knowledge and hold unrealistic expectations about labor. In the PP section, $68 \%$ of respondents noticed high anxiety regarding ability to breastfeed among AI women compared to women of other race-ethnic groups, as well as reluctance to take care of themselves (78\%) and of the baby (83\%). Sixtyfive percent of PP section respondents felt that AI women were more reluctant to go home at the time of discharge. 
AI women were also observed to display indirect indications of increased anxiety. Seventy-five percent of respondents reported that AI women were more likely to come to the hospital before active labor is established and ask the same question multiple times. While $44 \%$ of AP respondents felt that AI women were more likely to enroll in childbirth preparation classes, $17 \%$ believed that they were less likely to do so. More AP respondents believed that AI women were less likely to sign up for breastfeeding classes (29\%) than felt they were more likely to attend them (25\%). By the time of labor, AI women gave even less impression of having attended childbirth preparation or breastfeeding classes: $45 \%$ of IP respondents felt that AI patients were less likely to have attended those classes than women from other race-ethnic groups. AI women did not seem to feel themselves to be in control of their labor experience, nor likely to try to deal with their anxiety by preparation. Forty-three percent of AP section respondents indicated that $\mathrm{AI}$ women were less likely to have specific preferences for labor or to create a birth plan, while only $9 \%$ of respondents thought that AI women were more likely to do so.

In the narrative section, 18 respondents recommended that childbirth/breastfeeding/baby care classes be made mandatory for AI patients, or were specifically tailored to fit the needs of AI women.

\section{Heavy Reliance on Husband and}

Family Members for Decision-

Making and Care

Eighty-three percent of AP section respondents reported that husbands often accompany AI women to prenatal visits, compared to husbands or partners of patients from other race-ethnic groups. Ninety-one percent of AP section respondents noticed husbands asking multiple detailed questions more often. 
Eighty-seven percent of IP section respondents noticed that AI women were more likely to allow, or expect, their husbands to answer questions for them, including personal questions. Eighty-eight percent of respondents also observed AI women delegating more of the decisions regarding their own care in labor to their husbands.

In the PP section, providers also noted that AI women were more likely to delegate decision making regarding both their own care (83\%) and the baby's care (75\%) to their husbands or other family members. Eighty-seven percent of PP section respondents felt that AI women were more likely to rely on family members to take care of the baby upon returning home, and $65 \%$ of respondents also felt that AI women were more reluctant to go home at the time of discharge. At the same time, $47 \%$ of $\mathrm{PP}$ respondents reported that $\mathrm{AI}$ women were more likely to ask for nurses' help in managing their extended family during their hospital stay. This data raises the question of whether AI women's observed reluctance to take care of themselves and their baby is voluntary, or culturally imposed on the women.

Respondents of open-ended questions noticed that it is not uncommon for the AI women to be caught between the contradictory advice of family members and healthcare providers. They suggested including AI women's family members in breastfeeding and baby care classes during pregnancy. Some nurses suggested including family members in the hospital's teaching and decision-making processes. Other respondents mentioned family members not speaking English or conversing in their native language in front of the nurse as barriers to establishing therapeutic communication. 
Physical Demands and Pain During

Childbirth and Recovery

Respondents of the IP section observed that AI women were more likely to perceive early labor as extremely painful (75\%), have trouble following directions during labor (64\%), have trouble coordinating pushing efforts (79\%), have cesarean sections during the pushing stage due to lack of fetal descent (64\%), and have high rates of operative vaginal deliveries $(61 \%)$. Respondents of the PP section also reported that AI patients were more likely to have many complaints of physical discomfort (78\%).

When answering open-ended questions, many respondents mentioned intolerance of physical discomfort (such as having IV started or blood pressure measured), as well as general fatigue and lack of physical fitness, as factors that prevent AI women from pushing effectively. Among respondents who take care of women during pregnancy, many mentioned a high prevalence of PCOS and gestational diabetes. These diagnoses are often correlated with extra weight and lack of exercise, which some respondents also mentioned as a problem among AI women. Therefore, although the survey did not ask the question directly, AI women may have lower endurance during childbirth due to a lack of sufficient physical activity before or during pregnancy.

\section{Lack of Understanding of the Role of}

Nurses in American Healthcare

Respondents of the IP section noted that AI women more often give the impression that they do not trust nurses (59\%) and do not understand the role of nurses in the hospital (68\%). Sixty-nine percent of respondents also felt that the extended family members of AI women did not trust nurses and second-guessed nurses' advice. Both IP and PP sections respondents noted that AI women are 
more likely to keep asking the same question repeatedly $(88 \%$ and $87 \%$ respectively).

In the narrative section, many nurses wrote that they felt patients repeated the same questions to different healthcare professionals, as if they did not trust the first answer they heard. Many nurses perceived there to be an extra challenge in finding out if the AI patient understood and was satisfied with the answer she was given. Many nurses felt that AI patients only listened to the advice of their physicians, and treated nurses like "servants." I address this topic more in the next section.

\section{Research Question 3: What are Specific Challenges for Healthcare Professionals Caring for Asian Indian Women in a Reproductive/Perinatal Setting.}

As discussed in the previous section, many respondents felt that AI women are more likely than women from other race-ethnic groups to have low pain tolerance, experience difficulty tolerating pelvic exams, lack knowledge of reproductive health, rely on husbands for communication with healthcare providers, repeatedly ask the same questions, and misunderstand the role of nurses. All these factors present a unique challenge for healthcare providers caring for AI women.

I asked healthcare providers the following open-ended questions regarding their experience caring for AI patients.

1. Please indicate what you perceive as specific challenges for healthcare professionals taking care of Asian Indian women in reproductive/perinatal settings.

2. Is it more or less difficult for you to establish therapeutic relationships with Asian Indian patients? Why? 
Fifty-seven out of 76 respondents (75\%) answered the second question. Of those who answered, 31(54\%) felt that it was more difficult to establish a therapeutic relationship with AI patients. Six respondents (11\%) answered that it was not more difficult, but required more time and patience. Seven (12\%) wrote that it was "easy" or "less difficult" to take care of AI patients compared to patients from other race-ethnic groups, and $13(23 \%)$ said that it was about the same. L\&D nurses were more likely to find caring for AI patients to be especially challenging. Out of $18 \mathrm{~L} \& \mathrm{D}$ nurses, $12(67 \%)$ answered this question, and ten out of the $12(83 \%)$ indicated that it was more difficult to establish a therapeutic relationship with AI patients.

The following are examples of narrative answers to my question about establishing therapeutic communications with AI patients.

- "I feel therapeutic relationships are easy with Indian patients, they generally speak English well, are well educated and motivated to do the right thing for their babies" (Lactation Consultant).

- "Less difficult as they are usually well-educated and motivated to help themselves get healthier" (Primary Care Physician).

- "Generally feel able to establish good relationship, but often requires a lot of extra time/handholding/explanations/reassurance" (OB/GYN).

- "It can be challenging because they are not forthcoming about information and you have to specifically ask questions and ask it multiple times in different ways to make sure they understand' (APN).

- "More difficult than other ethnic groups, in part because of the larger proportion of engineering types (both patients \& spouses), in the population which we serve. This population has challenges understanding that the labor \& delivery process involves significant 'loss of control.' Cultural view of nurses 
as handmaidens, as lacking authority / expertise make establishing a therapeutic relationship more challenging" (L\&D nurse).

- "I feel it is more difficult because AI patients seem to be highly influenced by the opinions of their family members. This often affects how open the patient is to hearing information being taught by health care staff" (Mother-Baby Nurse).

- "I just wish they learn the system better since most of them work here and try to treat the people who help them in labor and delivery with mutual respect. I have to admit majority of them are thankful for the care they receive, maybe because I am a physician!!!!” (OB/GYN).

The following are some of the respondents' answers to the question about the challenges that healthcare professionals face when taking care of AI women.

- "Our general lack of understanding of their cultural practices around pregnancy and childbirth; communication difficulties (OB/GYN)."

- "Understanding the cultural experience of moving to a new husband with essentially a stranger and the lack of sexual education these woman have received from their mothers/friends" (Primary Care Physician).

- "Very sensitive to exams, severe anxiety, numerous questions, husbands answer for them (OB/GYN)."

- "Women who are too timid to address their medical concerns, husbands who are controlling of their wives medical concerns and care" (CNM).

- "Lack of understanding (by patient) of childbirth process, specifically the length of normal labor and the intensity of work involved" (L\&D nurse).

- "Even after going over teaching information I am not always sure if it is understood by the questions that continue to be asked" (Mother-Baby nurse). 
- "After delivery it is sometimes difficult to convince them to be self sufficient and to be able to take care of baby" (Mother-Baby nurse).

- "The most significant challenge is the limited time during their stay to educate them on everything they need to know to care of their infants after they are discharged" (Mother-Baby nurse).

- "Lack of expression of appreciation for nursing care given (Disruption in the cycle of caring, where nurses normally receive patients' appreciation which then fuels our desire/ability to give more). Feeling like whatever you do, it's not enough" (L\&D nurse).

- "Since I have been working with Asian Indian women, I have come to understand more about their culture, which makes it easier to interact with them and understand what they expect. I also feel that the longer Asian Indians have been in this country as a group, the more they have come to understand our culture and medical system and share this knowledge with their expectant friends" (Mother-Baby nurse).

In the final open-ended question, I asked what hospitals could do to improve the experience of AI women in the maternal-child health area. The respondents were unanimous in their recommendation that hospitals deliver more prenatal education to AI patients and their families. Respondents recommended that the prenatal education take AI culture into account. They also recommended that the AI patients' prenatal education include a component about the role and training of nurses. Additionally, respondents recommended additional training for hospital staff, which would educate the staff about culturally competent care for AI women. The following are some example answers to this final question. - "Offer tailored care, answer questions clearly, as often as needed" (CNM). 
- "Staff needs more cultural training to help in understanding and assisting this large percentage of our population. Ideally there would be culturally sensitive prenatal teaching for patients to help them as they enter the unfamiliar environment of an American hospital" (Mother-Baby nurse).

- "Maybe the website could be updated regarding the general birthing experience, the role of the nurses in labor and delivery and maternity explained in detail and reassuring and educating patients about the role and importance of nurses during their hospital stay. May be setting their expectations right might improve their experience" (OB/GYN).

- "Include family in teaching and decision making" (Lactation consultant).

- "Start their education early in the pregnancy. Educate them as to what to expect in L\&D. What we do. How we are trained and that we are competent" (L\&D nurse). 


\section{REPRODUCTIVE CHALLENGES OF ASIAN INDIAN WOMEN}

\section{CHAPTER 5: DISCUSSION AND CONCLUSION}

To date, this is the first study that has attempted to understand the reproductive challenges observed by healthcare providers (HCPs) who take care of Asian Indian women (AI) living in the southern San Francisco Bay Area, California.

\section{Perception of Asian Indian patients and their families}

Healthcare providers described AI patients as college-educated, with a good verbal command of the English language. HCPs also reported that many of their AI female patients have had long-distance marriages, in which they immigrated to the United States after marrying an AI man who was already living there. These findings correspond to the studies described in the literature review, which have shown the prevalence of arranged marriages both in India and in the Indian diaspora in the United States.

Although many of the AI patients discussed in this study came to the United States through marriage and live in nuclear families, family members tend to be very involved in the care of the new mother and the newborn. Grandparents often play major roles in the upbringing of children in India, and new mothers are expected to rest after birth for extended periods of time. New mothers might feel torn between their families' expectations of assuming care of the newborn, and HCPs' expectations that the mother remain autonomous and take the lead in her infant's care.

\section{Vaginismus and Unconsummated Marriage}

HCPs identified vaginismus (hypertonicity of the pelvic floor muscles, preventing the insertion of any object in the vagina), pain during intercourse, 
avoidance of intercourse, and unconsummated marriage as being significantly more prevalent among AI patients than patients of other race-ethnic groups. HCPs taking care of AI women in outpatient settings as well as in hospitals during labor reported increased incidence of pain during vaginal exams, or inability to tolerate vaginal exams.

These findings have not been previously described in studies inside or outside of India. To date, only one study (Ranade, 2011) has investigated the time it took AI couples in arranged marriages to consummate their marriages. In the study's small sample, couples took an average of one to three months to consummate their marriage, with some respondents taking more than a year.

Long-distance or arranged marriages, cultural taboos against discussing sex, lack of sex education, fear, and lack of vocabulary to describe what is happening are all factors that may play a role in the increased prevalence of problems with penetration in AI women. HCPs who are unaware of these issues may treat AI women for infertility, when lack of penetration may be the real cause of the problem. Furthermore, lack of understanding among HCPs may create recursive cycles of pain, fear, and tension among AI women, perpetuating their issues with vaginismus and pelvic exam difficulties.

\section{Prenatal Education}

Survey respondents' most common recommendation was to provide AI women with more prenatal education regarding the process of labor, breastfeeding, and newborn care. None of the providers in the study reported late start of prenatal care or lack of understanding of the importance of prenatal care as significant challenges when working with the AI population. Contrary to the suggestions of some of the authors discussed in the literature review, AI women in Silicon Valley 
do not appear to view pregnancy and birth as physiological processes not requiring medical attention. Rather, AI women in Silicon Valley ask more questions and have more anxieties about pregnancy, childbirth and breastfeeding than women from other race-ethnic groups, according to their HCPs. This is not surprising given the dramatic medicalization of childbirth in India in the last ten years, combined with India's continued lack of education about reproduction.

It is unclear if AI women in Silicon Valley are less likely to attend prenatal classes, or if the classes they do attend simply do not improve AI women's knowledge and confidence about childbirth, postpartum recovery, breastfeeding, and baby care. Providers answering questions regarding care during pregnancy (AP care) felt that AI women were only slightly less likely to attend childbirth preparation classes than women of other race-ethnic groups. However, providers who were involved in caring for AI women during labor (IP care) were much more likely to have had the impression that AI women had not attended childbirth preparation classes.

Some AI women may not be signing up for prenatal classes because of the lack of a direct recommendation from physicians. Couples may also be unwilling to pay for the services not covered by the insurance. For these reasons, couples may see prenatal classes as non-essential or redundant.

However, a quick inquiry in ECH MV childbirth preparation and breastfeeding classes registration revealed that $40 \%$ to $50 \%$ of attendees appeared to be Asian Indian. Therefore, it is likely that the education that AI women are receiving in childbirth preparation classes does not translate into confidence and knowledge during labor, childbirth, and breastfeeding. More research is needed to better understand this phenomenon. 
The Role of the Nurse

The physicians in this study noted the extra time and patience required for providing care to AI patients and recognized cultural differences in the communication styles of AI patients. However, they did not feel that establishing therapeutic communication with them was particularly challenging. Ladha (2010) found that South Asian women in her study were satisfied with their relationships with healthcare providers if the provider answered their questions. Women in that study preferred to have female care providers, valued continuity of care, and were upset if their doctor was not available during delivery. This corresponds to our findings that AI women are likely to expect their doctors to be heavily involved in labor and delivery.

By contrast, nurses in this study typically stated that AI patients and their families did not trust their judgment and did not understand their expertise level. That was especially pronounced for $L \& D$ nurses, who are typically the first to encounter patients when they come to the hospital during pregnancy and while in labor, and who care for the patients during the most acute, dramatic, and high-risk portion of their stay.

The role of the nurses during hospital childbirth in India is not welldescribed in literature. Although all registered nurses in India have dual license as registered nurses and midwives, their scope of practice is poorly defined and appears to be "circumstances driven" and physician-oriented. Bharati, Johansson, Prakasamma, Mavalankar, and Christensson (2013) describe a healthcare environment in which "the senior staff nurses managed the supplies and maintained records, while the junior staff nurses and the nursing students assisted the doctor" (p.633). The status of nurse therefore is very different from the status of physician in India; nurses are not perceived by patients as qualified to function 
without direct supervision from the physician. Okazaki (2000) notes that healthcare providers without titles such as "Doctor" or "Professor" after their names have relatively low ascribed credibility among Asian American clients, and must actively work to achieve credibility. My findings suggest that a similar situation appears to hold true for Asian Indians in Silicon Valley.

\section{CONCLUSION}

The findings of this study highlight the specific challenges observed by HCPs taking care of AI women in California's southern San Francisco Bay Area. Since these patients are often well-educated and tend to speak English well, HCPs may be underestimating specific cultural-related challenges in caring for this population. HCP need to be especially sensitive to increased difficulties in tolerating routine pelvic exams among AI women reported in this study, as well as issues such as unconsummated marriages, lack of knowledge about reproductive anatomy, and vaginismus.

Traditional childbirth education approaches may not work as effectively for AI women. Healthcare institutions need to develop culturally competent classes that address the specific concerns and needs of AI patients in order to increase these patients' confidence in their ability to labor, birth, and breastfeed their children. Furthermore, AI patients may need extra encouragement directly from their physicians to enroll in prenatal classes. Research is needed to understand better ways to deliver prenatal education to this population, such as via smaller groups separated by gender, or with classes that include extended family members who will be involved in decision-making and baby care.

While the general American population has been naming nursing "the most trusted profession" for years, patients coming from India do not seem to have the 
same concept of nursing. These patients may need extra help and preparation to understand the role of nurses in the American healthcare system. At the same time, nurses and other healthcare providers need to be educated on the specifics of Indian culture in order to provide culturally competent care to this population. Campinha-Bacote (2007) defined cultural competence as an ongoing process in which healthcare providers continuously strive to improve their ability to work effectively within the cultural context of the patient. Further research is needed to understand the unique reproductive challenges and needs of AI women and the best ways to improve healthcare delivery for this population. This study has identified a number of areas to investigate for a better understanding of AI women's specific needs, such as how to better educate and prepare AI women for childbirth and breastfeeding, and how to help AI women discuss and treat vaginismus-related problems in a culturally competent way. Additionally, this study recommends developing continuous education programs for healthcare providers, which will help them address their personal biases while enhancing their understanding of cultural and situational factors shaping the healthcare expectations and needs of AI women. 
REPRODUCTIVE CHALLENGES OF ASIAN INDIAN WOMEN

REFERENCES 


\section{REPRODUCTIVE CHALLENGES OF ASIAN INDIAN WOMEN REFERENCES}

Aggarwal, R., Mishra, V., Panchal, N. , Patel, N., Deshchougule, V., et al. (2012). Sexual dysfunction in women: An overview of risk factors and prevalence in Indian women. Journal of South Asian Federation of Obstetrics and Gynecology, 4(3), 134-136.

Assanand, S., Dias, M., Richardson, E., Chambers, N, \& Waxier-Morrison, N. (2005). People of South Asian descent. In N. Waxier-Morrison, J. Anderson, E. Richardson, \& N. Chambers (Eds.), Cross Cultural Caring: A Handbook for Health Professionals ( $2^{\text {nd }}$ ed.). (pp.197-246). Vancouver, BC: UBC.

Beach , M., Saha, S., Cooper, L. (2006) The role and relationship of cultural competence and patient-centeredness in healthcare quality. The Commonwealth Fund. Retrieved from http://www.commonwealthfund.org/ /media/files/publications/fundreport/2006/oct/the-role-and-relationship-of-cultural-competence-andpatient-centeredness-in-health-carequality/beach_rolerelationshipcultcomppatient-cent_960-pdf.pdf

Bharati, S., Johansson, E., Prakasamma, M., Mavalankar, D., Christensson, K. (2013). Midwifery scope of practice among staff nurses: A grounded theory study in Gujarat, India. Midwifery 26, 6-633.

Boi, S. (2000). Nurses' experiences in caring for patients from different cultural backgrounds. Journal of Research in Nursing, 5(5), 382-389.

Bottorff, J.L., Johnson, J.L., Venables, L.J., Grewal, S., Popatia, N., Hilton, A.B., Clarke, H., Sumel, P., Bilkhu, S., \& Sandhu, G. (2001). Voices of Immigrant South Asian women: Expression of health concerns. Journal of health care for the poor and underserved, 12(4), 392-403.

Brar, S., Tang, S., Drummond, N., Palacios-Derflinger, L., Clark, V., John, M., \& Ross, S. (2009). Perinatal care of South Asian immigrant women and women born in Canada: Telephone survey of users. Journal of Obstetrics and Gyneacology, 31(8), 708-716.

Campinha-Bacote, J. (2007). The process of cultural competence in the delivery of healthcare services: The journey continues (5th Ed.). Cincinnati, OH: Transcultural C.A.R.E. Associates. 
Campinha-Bacote, J., (2011). Delivering patient-centered Care in the midst of a cultural conflict: The role of cultural competence" OJIN: The Online Journal of Issues in Nursing, 16(2). Retrieved from http://www.nursingworld.org/MainMenuCategories/ANAMarketplace/ANA Periodicals/OJIN/TableofContents/Vol-16-2011/No2-May-2011/DeliveringPatient-Centered-Care-in-the-Midst-of-a-Cultural-Conflict.html

Callister, L. (1995). Cultural meanings of childbirth. Journal of Obstetric, Gynecologic, and Neonatal Nursing: JOGNN / NAACOG,24(4), 327-334.

Char, S. (2005, July 1). Marking Time. India Currents. Retrieved from https://www.indiacurrents.com/articles/2005/07/01/marking-time

Chaudhuri, B. (2011). Skilled migration from India to the United States: Contextualizing in the backdrop of global economic crisis. Indian Journal of Economics \& Business, 10(2/3), 249-266.

Choudhry, K., \& Wallace, L. (2012). 'Breast is not always best': South Asian women's experiences of infant feeding in the UK within an acculturation framework. Maternal \& Child Nutrition, 8(1), 72-87.

Cioffi, J. (2004). Caring for women from culturally diverse backgrounds: Midwives' experiences. Journal of Midwifery \& Women's Health, 49(5), 437-442.

Cowin, J. (1999). The breastfeeding experiences and decision-making influences of South Asian women in Vancouver, Canada. Retrieved from ProQuest, UMI Dissertations Publishing.

Dasgupta, S. (1998). Gender roles and cultural continuity in the Asian Indian immigrant community in the U.S. Sex Roles, 38(11), 953-974.

Desai, S., \& Andrist, L. (2010). Gender scripts and age at marriage in India. Demography, 47(3), 667-687.

El Camino Hospital Marketing and Communications. (2013). Maternity Focus Groups; Patient Satisfaction. Mountain View, CA: Ernst, C.

Facchini, G. \& Lodigiani, E. (2014). Attracting skilled immigrants: An overview of recent policy developments in advanced countries. National Institute Economic Review, 229(1), R3-R21. 
Fisher, J., Bowman, M., \& Thomas, T. (2003). Issues for South Asian Indian patients surrounding sexuality, fertility, and childbirth in the US health care system. J Am Board Family Practice, 16, 151-155.

Ghosh, S. (2010). Increasing trend in caesarean section delivery in India: Role of medicalization of maternal health. The Institute for Social and Economic Change, Bangalore. Retrieved from http://www.isec.ac.in/WP\%20236\%20-\%20Sancheeta\%20Ghosh.pdf

Handa, V., Danielsen, B., \& Gilbert, W. (2001). Obstetric anal sphincter lacerations. Obstetrics \& Gynecology, 98(2), 225-230.

Hopkins, L., Caughey, A., Glidden, D., \& Laros, R. (2005). Racial/ethnic differences in perineal, vaginal and cervical lacerations. American Journal of Obstetrics and Gynecology, 193(2), 455-459.

Hoskins, I. A. (2004). Perinatal health care issues of Pakistani women. In M.A. Shah \& D. Campbell (Eds.), Transcultural aspects of perinatal health care: A resource guide. Tampa, FL: National Perinatal Association.

Im E. (2009). Meleis transition theory. In M.R. Alligood \& A.M. Tomey (Eds.), Nursing theorists and their work (7th ed.). St Louis, MO: Mosby.

Institute of Medicine. (2001). Crossing the quality chasm: a new health system for the $21^{\text {st }}$ century. Washington, DC: National Academy of Science.

Institute of Medicine. (2002). Unequal Treatment: Understanding Racial and Ethnic Disparities in Health Care". Washington DC: National Academy of Science.

Kakar, S. (2009). The Inner World. A Psychological Study of Childhood and Society in India (3rd ed.). New Delhi: Oxford University Press.

Kakar, S. \& Kakar, K. (2007). The Indians: Portrait of a People. London: Penguin Books.

Kannan, S., Carruth, B.R., \& Skinner, J. (1999). Infant feeding practices of Anglo American and Asian Indian American mothers. Journal of the American College of Nutrition, 18(3), 279-86.

Kelkar, M. (2012). South Asian immigration in the United States: A gendered perspective. Asian American Policy Review, 22, 55-60. 
Kreisberg, N. (2014 April 8) H1B Jobs: Filling the skills gap. American Institute for Economic Research. Retrieved from https://www.aier.org/research/h1bjobs-filling-skill-gap

Ladha, R. (2010). South Asian women's perspectives about pregnancy needs and utilization of Canadian prenatal health services. Retrieved from ProQuest, UMI Dissertations Publishing.

Mehrotra, M., \& Calasanti, T. (2010). The family as a site for gendered ethnic identity work among Asian Indian immigrants. Journal of Family Issues, 31(6), 778-807.

Meleis, A., Sawyer, L., Im, E., Hilfinger Messias, D., \& Schumacher, K. (2000). Experiencing transitions: An emerging middle-range theory. ANS. Advances in Nursing Science, 23(1), 12-28.

Meleis, A. (2010). Transitions Theory: Middle Range and Situation Specific Theories in Research and Practice. New York, NY: Springer Publishing Company.

Merry, L., Small, R., Blondel, B., \& Gagnon, A. (2013). International migration and caesarean birth: A systematic review and meta-analysis. BMC Pregnancy and Childbirth, 13(1), 27.

Nagpal, J., Sachdeva, A., Sengupta Dhar, R., Bhargava V.L., Bhartia A. (2015). Widespread non-adherence to evidence-based maternity care guidelines: A population-based cluster randomised household survey. British Journal of Obstetrics and Gynecology, 122, 238-248

Okazaki, S. (2000). Assessing and treating Asian Americans: Recent advances. In I. Cuellar \& F. A. Paniagua (Eds.), Handbook of Multicultural Mental Health: Assessment and Treatment of Diverse Populations. San Diego: Academic Press.

Ottani, P. (2002). When childbirth preparation isn't a cultural norm. International Journal of Childbirth Education, 17(2), 12.

Pacquiao, D., Douglas, M., Rosenkoetter, M., Pacquiao, D.F., Callister, L.C., Hattar-Pollara, M., Lauderdale, J., Milstead, J., Nardi, D., Purnell, L. (2014). Guidelines for implementing culturally competent nursing care. Journal of Transcultural Nursing, 25(2), 109-121. 
Patel, N. (2007). The construction of South-Asian-American womanhood: Implications for counseling and psychotherapy. Women \& Therapy, 30(3-4), 51-61.

Patel, R. (2013, Jan 24) Education: The only way to cure India's rape epidemic. Tehelka.com Retrieved from http://www.tehelka.com/education-the-onlyway-to-cure-indias-rape-epidemic/

Pew Charitable Trust. (2012). The rise of Asian Americans. Retrieved form http://www.pewsocialtrends.org/asianamericans-graphics/indians/

Price, T. (2011). The lived experiences of Asian Indian immigrants adapting to life in the United States. Retrieved from ProQuest, UMI Dissertations Publishing

Purnell, L. (2014). Guide to Culturally Competent Health Care. Philadelphia, PA: F.A. Davis Co.

Ranade, N. (2011). Transition to arranged marriages among Asian-Indian newlywed couples in India and the U.S. Retrieved from ProQuest, UMI Dissertations Publishing.

Rao, A., Daniels, K., El-Sayed, Y., Moshesh, M., \& Caughey, A. (2006). Perinatal outcomes among Asian American and Pacific Islander women. American Journal of Obstetrics and Gynecology, 195(3), 834-838.

Rashidi, A., \& Rajaram, S. (2001). Culture care conflicts among Asian-Islamic immigrant women in US hospitals. Holistic Nursing Practice, 16(1), 55-64.

Reynolds, F., \& Shams, M. (2005). Views on cultural barriers to caring for South Asian women. British Journal of Midwifery, 13(4), 236-242.

South Asian Americans Leading Together. (2012). Resources and Factsheets. Retrieved from: http://saalt.org/south-asians-in-the-us/factsheets-andresources/

Sathyamurthy, M., \& Raj, S. (2012). A comparison of traditional beliefs, practices and health seeking behaviors that influence dietary practices during pregnancy of South Asian Indian women in India and the United States. Journal of the Academy of Nutrition and Dietetics, 112(9), A20.

Seervai, S. (2015, Jan 30) Outsourcing sex education in India. India Real Time: Wall Street Journal blog. Retrieved from: http://blogs.wsj.com/indiarealtime/2015/01/30/indsex/ 
Singh G. \& Gupta E. D. (2013). Rising incidence of caesarean section in rural area in Haryana, India: A retrospective analysis. The Internet Journal of Gynecology and Obstetrics, 17(2). Retrieved from https://ispub.com/IJGO/17/2/2972\#

Singh, J., Tharyan, P., Kekre, N., Singh, G., \& Gopalakrishnan, G. (2009). Prevalence and risk factors for female sexual dysfunction in women attending a medical clinic in South India. Journal of Postgraduate Medicine, 55(2), 113-120.

Sivakumar, N. (2004). Stop the H1B bashing; CNN news anchor Lou Dobbs probably doesn't know that there are millions of immigrant techies living in the United States. EWeek, 21(40), 60.

Spitzer, D. (2007). Immigrant and refugee women: Recreating meaning in transnational context. Anthropology in Action: Journal for Applied Anthropology in Policy and Practice, 14(1-2), 52-62.

Suxton, A. \& Kumar, S. (2013) The rapes go on. How do we? Tehelka.com. Retrieved from http://www.tehelka.com/the-rapes-go-on-howdo-we/

Sweas, M. (2012, May 11). Unable to work Indian immigrant women turn to spiritual practices for comfort. Huffington Post. Retrieved from http://www.huffingtonpost.com/2012/05/11/unable-to-work-indianimmigrant-women-spiritual-practices_n_1508261.html

U.S. Census Bureau. (2000). 2000 Census. Retrieved from http://www.census.gov/census2000/

U.S. Census Bureau. (2010). 2010 Census. Retrieved from http://www.census.gov/2010census/

U.S. Citizenship and Immigration Services. (2012). Characteristics of H1B Specialty Occupation Workers. Retrieved from http://www.uscis.gov/sites/default/files/USCIS/Resources/Reports\%20and\% 20Studies/H-1B/h1b-fy-12-characteristics.pdf

Uberoi, P. (2006) Freedom and Destiny. Gender, Family and Popular Culture in India. New Delhi: Oxford University Press. 
Ustinova, A. (2008, March 9). Indian women isolated in Silicon Valley. San Francisco Chronicle. Retrieved from http://www.sfgate.com/bayarea/article/Indian-women-isolated-in-SiliconValley-3223634.php

Varghese, K., Bansal, R., Kekre, A., \& Jacob, K. (2012). Sexual dysfunction among young married women in southern India. International Urogynecology Journal, 23(12), 1771-1774.

Verma, K., Khaitan, B., \& Singh, O. (1998). The frequency of sexual dysfunctions in patients attending a sex therapy clinic in north India. Archives of Sexual Behavior, 27(3), 309-314.

Vora, K., Mavalankar, D., Ramani, K., Upadhyaya, M., Sharma, B., Iyengar, S, Gupta, V., \& Iyengar, K. (2009). Maternal health situation in India: A case study. Journal of Health, Population and Nutrition, 27(2), 184-201.

Vydelingum, V. (2006). Nurses' experiences of caring for South Asian minority ethnic patients in a general hospital in England. Nursing Inquiry, 13(1), 2332 .

Wagle, A., Varma, S., \& Sucher, K. (2009). Dietary behaviors and practices of pregnant and lactating South Asian women living in the United States. Journal of the American Dietetic Association, 109(9), A61.

Waxier-Morrison N., Anderson, J., Richardson E., Chambers N. (Eds.). (2005). Cross Cultural Caring: A Handbook for Health Professionals ( $2^{\text {nd }}$ ed.). Vancouver, BC: UBC.

Wong, L., Caughey, A., Nakagawa, S., Kaimal, A., Tran, S., \& Cheng, Y. (2008). Perinatal outcomes among different Asian-American subgroups. American Journal of Obstetrics and Gynecology, 199(4), 382.e1-382.e6.

Wilson, L. (2012). Cultural competence: Implications for childbearing practices. International Journal of Childbirth Education, 27(1), 10-17. 
APPENDICES 
REPRODUCTIVE CHALLENGES OF ASIAN INDIAN WOMEN

APPENDIX A: INVITATION TO PARTICIPATE IN THE STUDY 


\section{REPRODUCTIVE CHALLENGES OF ASIAN INDIAN WOMEN}

Dear colleagues,

I am Olga Libova, a certified nurse-midwife in Santa Clara County, working on Doctor in Nursing Practice degree with my committee chair, Dr.

Deepika Goyal. My project, “Healthcare Professionals' Perceptions of Reproductive Challenges and Experiences Among Asian Indian Women Coming to Silicon Valley" aims to further investigate reproductive challenges that you might have observed when working with immigrant Asian Indian (AI) population. Please see the link to the survey below.

\section{http://tinyurl.com/aiwomensurvey}

The survey is intended for nurses, physicians, midwives and lactation consultants taking care of AI women. It includes questions that cover the whole spectrum of a woman's reproductive journey from establishing an intimate relationship with her spouse through pregnancy and recovery after childbirth. There are a few general questions and then you are asked to compare your perceptions of challenges among Asian Indian women versus women from other race/ethnic groups in your care using Likert-scale questions. The survey allows you to skip the parts that are not applicable to your role.

This survey should take no more than 10 minutes to complete, is completely anonymous, and will not ask for any self-identifying information. I greatly appreciate your time and willingness to share your experiences. 
If you have any questions, concerns or comments, please feel free to contact me at midwife@gmail.com or my committee chair, Dr. Deepika Goyal at Deepika.goyal@sjsu.edu

Thank you!

Olga Libova, DNP(c), MS, CNM, RN 
APPENDIX B: PROVIDER SURVEY 


\section{Provider Survey}

\section{Demographic Data}

Thank you for participating in this survey gathering data about unique reproductive challenges and experiences among Asian Indian women In Silicon Valley.

Please start by answering some basic demographic questions and sharing your general impressions of reproductive challenges of Asian Indian women in your care. In following sections you will be asked to compare the prevalence of certain problems in Asian Indian patients versus patients from other race-ethnic groups under your care.

If you do not encounter these problems in your practice or do not have an answer, please leave the answer blank.

At the end of this survey you will have another opportunity to share your observations and suggestions.

Your participation in this survey is completely voluntary and anonymous. Submission of this survey indicates your consent to participate in this research.

\section{Occupation}

Mark only one oval.
Labor and Delivery Nurse
Mother Baby Nurse
$\mathrm{OB} / \mathrm{GYN}$
Primary Care Physician
Certified Nurse-Midwife
Advanced Practice Nurse
Lactation Consultant
Other:

2. Gender

Mark only one oval.

Female

Male

Decline 
3. Ethnicity

Mark only one oval.

Asian Indian

Chinese

Filipino

Japanese

Native American

African American

Latino

Caucasian

Decline

Other:

4. Age

Mark only one oval.

under 30

C 30 to 50

over 50

$\bigcirc$ decline

5. Please indicate which type of patients you see below:

Mark only one oval.

outpatient only

inpatient: labor and delivery only

inpatient: postpartum only

inpatient only: both labor and delivery and postpartum

both inpatient and outpatient

Other: 
6. Please indicate if you are associated with any hospital below:

If more than one, please choose the one where you encounter most Asian Indian women Mark only one oval.

None

El Camino Mountain View

El Camino Los Gatos

Good Samaritan

Kaiser

Stanford - Lucille Packard

O'Connor

Other:

\section{Description of the Asian Indian Population under Your Care}

7. Please indicate below approximately what percentage of your patients self-identify as Asian Indian women

Mark only one oval.

$10 \%$ or less

$11 \%$ to $30 \%$

$31 \%$ to $50 \%$

$51 \%$ to $70 \%$

$71 \%$ to $90 \%$

$90 \%$ or more

8. Please indicate your general perception of how well your Asian Indian female patients are able to verbally communicate in English?

Mark only one oval.

$\begin{array}{lllll}1 & 2 & 3 & 4 & 5\end{array}$

barely or not at all $\square \longrightarrow \square$ very fluently

9. Please indicate your general perception of what percentage of your Asian Indian female patients have college education and above?

Mark only one oval.

Cannot answer

Less than $25 \%$

$25 \%$ to $50 \%$

$51 \%$ to $75 \%$

More than $75 \%$ 
10. Please estimate, in your opinion, what percentage of your Asian Indian female patients came to the US after marrying an Asian Indian man who was already living in the US

Mark only one oval.

Cannot answer

Less than $25 \%$

$25 \%$ to $50 \%$

$51 \%$ to $75 \%$

More than $75 \%$

11. Please indicate most common reproductive/perinatal challenges you observe among Asian Indian female patients

Please list as many as you find relevant.

12. Please indicate what you perceive as specific challenges for healthcare professionals taking care of Asian Indian women in reproductive/perinatal setting

Please list as many as you find relevant.

\section{Outpatient Reproductive Care}

13. Questions in this section are intended for MDs/DOs, CNMs and NPs who provide outpatient (office) care including pelvic exams and discussions of sexual and reproductive health issues

Mark only one oval. 14.

I provide these services and would like to answer the questions Skip to question

I do not provide these services or do not want to answer - you will be taken to the next section Skip to question 25.

\section{Outpatient Reproductive Care}




\section{ethnic groups you provide care for.}

For each healthcare issue below, please rate them based on whether they occur less or more frequently among Asian Indian women compared to women of other race-ethnic group in your practice:

1 - Occurs significantly LESS often in Asian Indian women

2 - Occurs somewhat LESS often in Asian Indian women

3 - Occurs at the SAME rate in Asian Indian women as the rest of population

4 - Occurs somewhat MORE often in Asian Indian women

5 - Occurs significantly MORE often in Asian Indian women

Please leave blank if not applicable or you do not have an answer ---

\section{Unconsummated marriage}

Mark only one oval.

$\begin{array}{lllll}1 & 2 & 3 & 4 & 5\end{array}$

significantly less often in

Asian Indian women
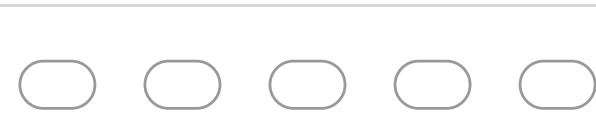

significantly more

often in Asian

Indian women

15. Difficulty achieving penetration during intercourse

Mark only one oval.

$\begin{array}{lllll}1 & 2 & 3 & 4 & 5\end{array}$

significantly less often in

Asian Indian women

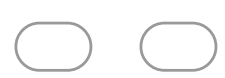

$\square \longrightarrow$

significantly more

often in Asian

Indian women

16. Pain during intercourse

Mark only one oval.

$\begin{array}{lllll}1 & 2 & 3 & 4 & 5\end{array}$

significantly less often in

Asian Indian women

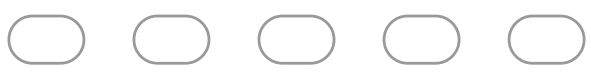

significantly more

often in Asian

Indian women

\section{Avoidance of intercourse}

Mark only one oval.

$\begin{array}{lllll}1 & 2 & 3 & 4 & 5\end{array}$

significantly less often in Asian Indian

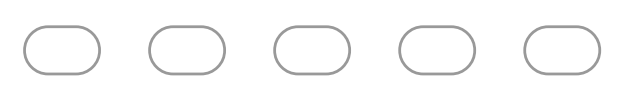

significantly more often in Asian Indian women 
18. Lack of knowledge regarding human sexuality and reproductive anatomy

Mark only one oval.

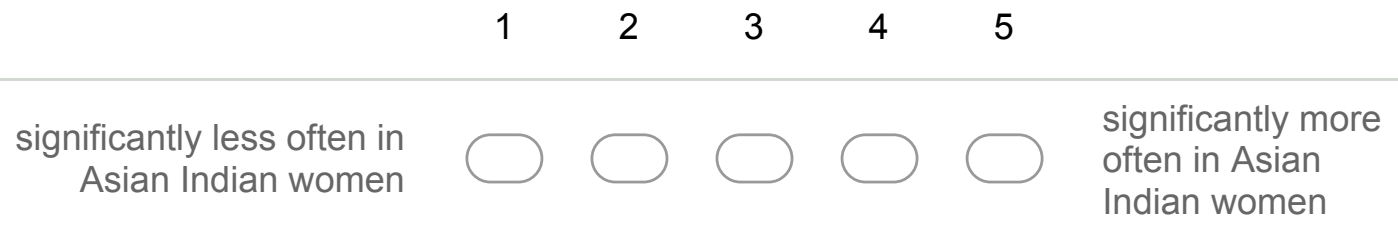

19. Appear reluctant to self-report sexual problems during office visits Mark only one oval.

$\begin{array}{lllll}1 & 2 & 3 & 4 & 5\end{array}$

significantly less often in

Asian Indian women

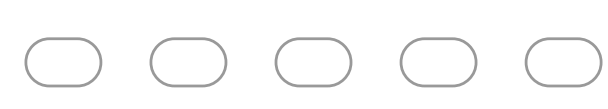

significantly more

often in Asian

Indian women

20. When prompted, report partner/husband showing symptoms of low desire or other sexual function problems

Mark only one oval.

significantly less often in
Asian Indian women

21. Appear reluctant to discuss birth control

Mark only one oval.

$\begin{array}{lllll}1 & 2 & 3 & 4 & 5\end{array}$

significantly less often in

Asian Indian women

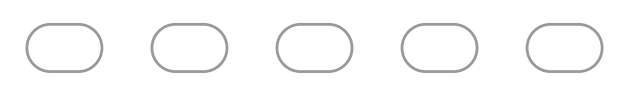

significantly more

often in Asian

Indian women

22. Report not using contraception while not desiring pregnancy

Mark only one oval.

$\begin{array}{lllll}1 & 2 & 3 & 4 & 5\end{array}$

significantly less often in

Asian Indian women

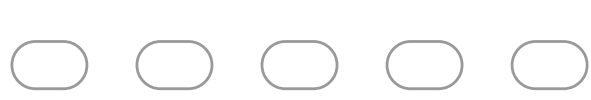

significantly more

often in Asian

Indian women 
23. Unable to undergo pelvic and/or speculum exam

Mark only one oval.

significantly less often in
Asian Indian women

24. Report or appear to experience pain (more than expected discomfort) during pelvic and/or speculum exam

Mark only one oval.

significantly less often in
Asian Indian women

\section{Pregnancy}

25. Questions in this section are intended for MDs/DOs, CNMs and NPs who provide outpatient (office) care during pregnancy

Mark only one oval.

I provide care during pregnancy and would like to answer the questions Skip to question 26.

I do not provide care during pregnancy or do not want to asnwer the questions - you will be taken to the next section Skip to question 38.

\section{Outpatient Care During Pregnancy}

\section{Comparison of Asian Indian women to women of other race- ethnic groups you provide care for}

For each healthcare issue below, please rate them based on whether they occur less or more frequently among Asian Indian women compared to women of other race-ethnic group in your practice:

1 - Occurs significantly LESS often in Asian Indian women

2 - Occurs somewhat LESS often in Asian Indian women

3 - Occurs at the SAME rate in Asian Indian women as the rest of population

4 - Occurs somewhat MORE often in Asian Indian women

5 - Occurs significantly MORE often in Asian Indian women

----- Please leave blank if not applicable or you do not have an answer----- 
26. Appear exceedingly anxious about pregnancy

Mark only one oval.

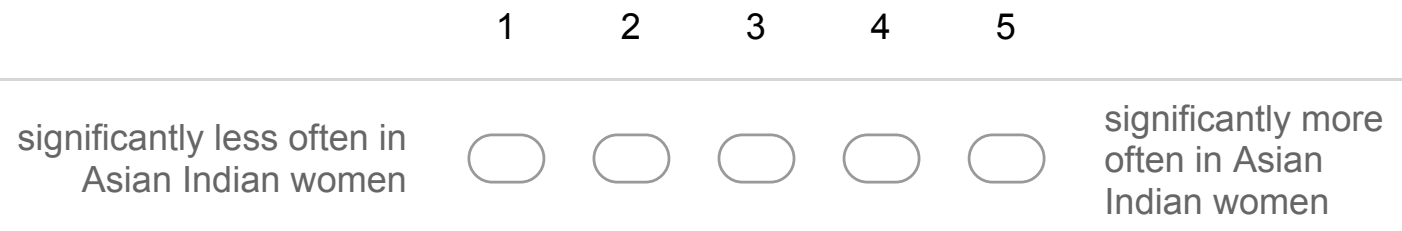

27. Seek very specific guidance for nutrition, activities and self care

Mark only one oval.

significantly less often in
Asian Indian women

28. Are more likely to use after hours answering services

Mark only one oval.

$\begin{array}{lllll}1 & 2 & 3 & 4 & 5\end{array}$

significantly less often in

Asian Indian women

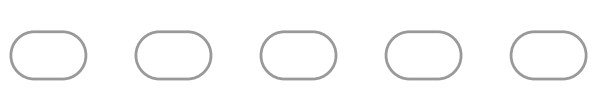

significantly more

often in Asian

Indian women

29. Appear disappointed if pregnant with female fetus

Mark only one oval.

significantly less often in
Asian Indian women

30. Have excessive anxiety about upcoming birth

Mark only one oval.

$\begin{array}{lllll}1 & 2 & 3 & 4 & 5\end{array}$

significantly less often in

Asian Indian women

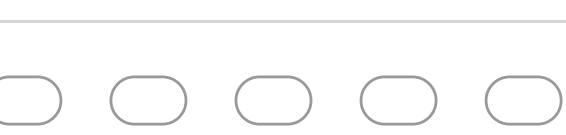

significantly more

often in Asian

Indian women 
31. Attend childbirth preparation classes

Mark only one oval.

significantly less often in
Asian Indian women

32. Attend breastfeeding preparation classes

Mark only one oval.

$\begin{array}{lllll}1 & 2 & 3 & 4 & 5\end{array}$

significantly less often in

Asian Indian women

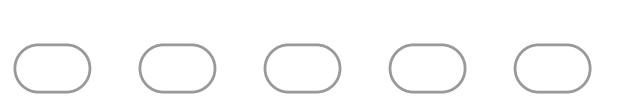

significantly more

often in Asian

Indian women

33. Have specific preferences for labor and create a birth plan

Mark only one oval.

$\begin{array}{lllll}1 & 2 & 3 & 4 & 5\end{array}$

significantly less often in

Asian Indian women

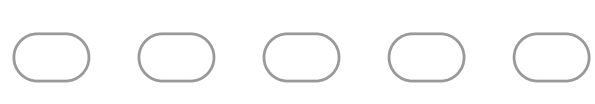

significantly more

often in Asian

Indian women

34. Request induction of labor for non-medical indications

Mark only one oval.

$\begin{array}{lllll}1 & 2 & 3 & 4 & 5\end{array}$

significantly less often in

Asian Indian women

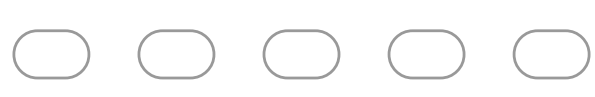

significantly more

often in Asian

Indian women

35. Request cesarean section for non-medical indications

Mark only one oval.

$\begin{array}{lllll}1 & 2 & 3 & 4 & 5\end{array}$

significantly less often in

Asian Indian women

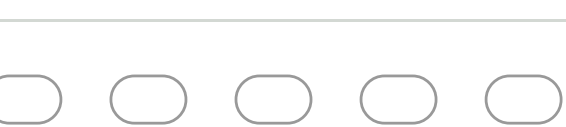

significantly more

often in Asian

Indian women 
36. Husband/partner accompanies patient to most appointments

Mark only one oval.

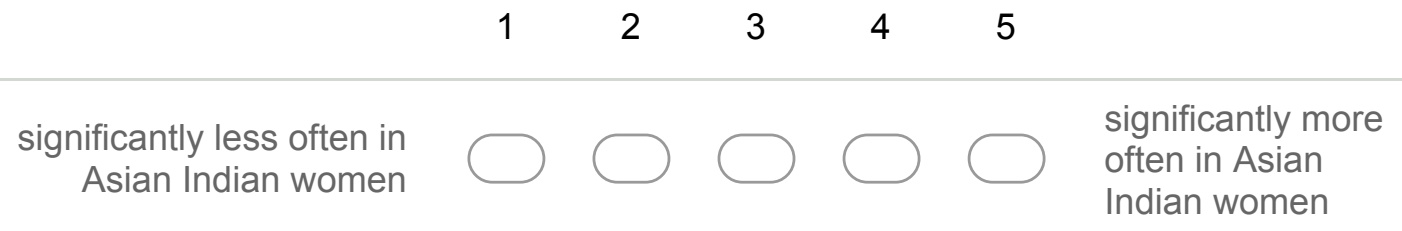

37. Husband/partner has multiple questions and concerns regarding pregnancy Mark only one oval.

significantly less often in
Asian Indian women

\section{Labor and Birth}

38. This section focuses on care of women during labor and birth and is intended for L\&D nurses, OB/GYNs, CNMs

Many of these questions refer to nursing care. If you are a physician or a midwife and feel that some questions do not apply to you or you cannot answer them, please just skip them

Mark only one oval.

I provide care during labor and birth and would like to answer the questions Skip to question 39.

I do not provide care during labor and birth or do not want to answer - you will be taken to the next section Skip to question 59.

\section{Inpatient Care during Labor and Birth}

\section{Comparison of Asian Indian women to women of other race- ethnic groups you provide care for}

For each healthcare issue below, please rate them based on whether they occur less or more frequently among Asian Indian women compared to women of other race-ethnic group in your practice:

1 - Occurs significantly LESS often in Asian Indian women

2 - Occurs somewhat LESS often in Asian Indian women

3 - Occurs at the SAME rate in Asian Indian women as the rest of population

4 - Occurs somewhat MORE often in Asian Indian women

5 - Occurs significantly MORE often in Asian Indian women

----- Please leave blank if not applicable or you do not have the answer --- 
39. Appear excessively anxious about labor

Mark only one oval.

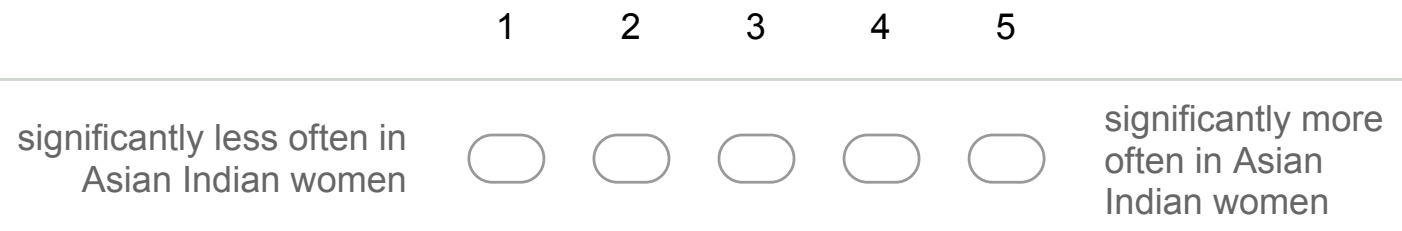

40. Tend to arrive in the hospital before active labor is established

Mark only one oval.

$\begin{array}{lllll}1 & 2 & 3 & 4 & 5\end{array}$

significantly less often in

Asian Indian women

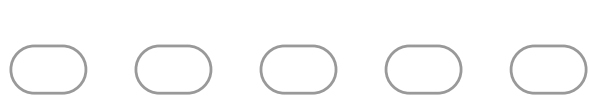

significantly more

often in Asian

indian women

41. Give impression that they do not trust nurses

Mark only one oval.

$\begin{array}{lllll}1 & 2 & 3 & 4 & 5\end{array}$

significantly less often in

Asian Indian women

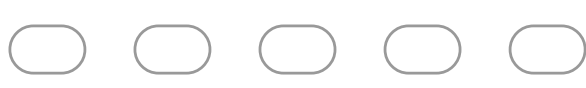

significantly more

often in Asian

Indian women

42. Give impression that they do not understand the role of the nurses in the hospital Mark only one oval.

significantly less often in
Asian Indian women

43. Tend to ask the same questions many times

Mark only one oval.

$\begin{array}{lllll}1 & 2 & 3 & 4 & 5\end{array}$

significantly less often in Asian Indian women

0000


44. Experience difficulty tolerating pelvic exams during labor

Mark only one oval.

significantly less often in
Asian Indian women

45. Perceive early labor as extremely painful

Mark only one oval.

$\begin{array}{lllll}1 & 2 & 3 & 4 & 5\end{array}$

significantly less often in

Asian Indian women

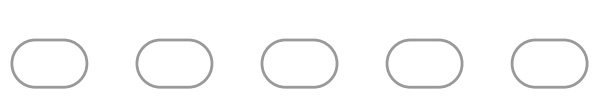

significantly more

often in Asian

Indian women

46. Are having hard time following directions during labor

Mark only one oval.

$\begin{array}{lllll}1 & 2 & 3 & 4 & 5\end{array}$

significantly less often in

Asian Indian women

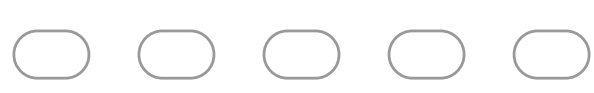

significantly more

often in Asian

Indian women

47. Are less likely to have attended childbirth preparation or breastfeeding classes Mark only one oval.

$\begin{array}{lllll}1 & 2 & 3 & 4 & 5\end{array}$

significantly less often in

Asian Indian women

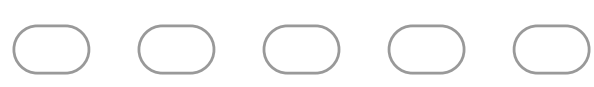

significantly more

often in Asian

Indian women

48. Appear to have little knowledge and unrealistic expectations of labor

Mark only one oval.

$\begin{array}{lllll}1 & 2 & 3 & 4 & 5\end{array}$

significantly less often in

Asian Indian women

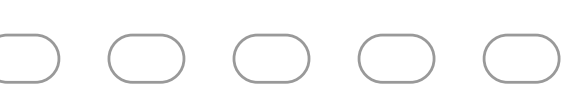

significantly more

often in Asian

Indian women 
49. Have hard time coordinating pushing efforts

Mark only one oval.

significantly less often in
Asian Indian women $\longrightarrow$

50. Have a cesarean section in pushing stage due to lack of fetal descent

Mark only one oval.

$\begin{array}{lllll}1 & 2 & 3 & 4 & 5\end{array}$

significantly less often in

Asian Indian women

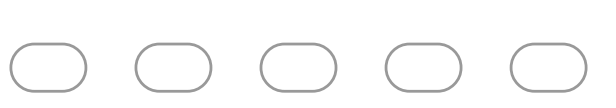

significantly more

often in Asian

Indian women

51. Have increased perineal trauma (3rd and 4th degree lacerations)

Mark only one oval.

$\begin{array}{lllll}1 & 2 & 3 & 4 & 5\end{array}$

significantly less often in

Asian Indian women

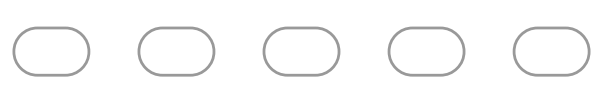

significantly more

often in Asian

Indian women

52. Have high rate of operative vaginal deliveries (forceps, vacuum extractors)

Mark only one oval.

significantly less often in
Asian Indian women $\longrightarrow$

53. Appear unsatisfied with their birth experience

Mark only one oval.

$\begin{array}{lllll}1 & 2 & 3 & 4 & 5\end{array}$

significantly less often in

Asian Indian women 
54. Expect/allow husband/partner to answer questions addressed to the patient, including personal questions

Mark only one oval.

significantly less often in
Asian Indian women

55. Defer to husband/partner for making decisions regarding her own care

Mark only one oval.

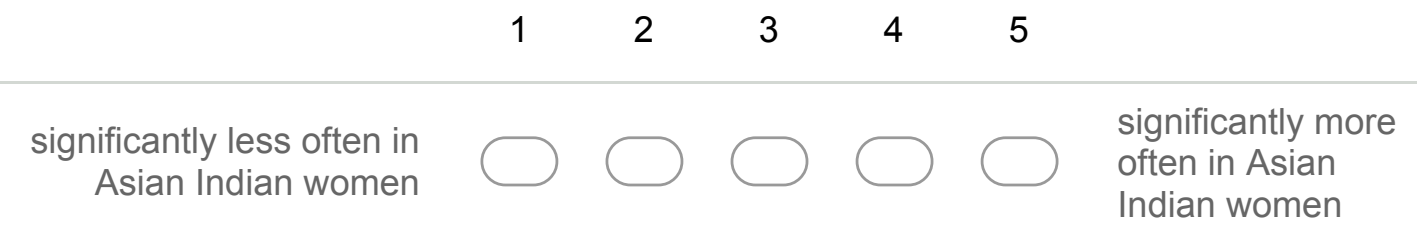

56. Extended family members provide hands-on support to laboring woman

Mark only one oval.

significantly less often in
Asian Indian women

57. Extended family members are likely to be present in the room during pushing Mark only one oval.

significantly less often in
Asian Indian women

58. Extended family members give impression that they do not trust nurses and second guess their advice.

Mark only one oval.

$\begin{array}{lllll}1 & 2 & 3 & 4 & 5\end{array}$

significantly less often in

Asian Indian women

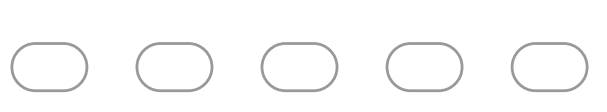

significantly more

often in Asian

Indian women

\section{Postpartum Care}


59. This section refers to inpatient care of women after birth and is mostly geared towards postpartum nurses and lactation consultants

If you answered the section on care during labor please feel free to skip this section Mark only one oval.

I provide postpartum care and would like to answer the questions Skip to question 60. I do not provide postpartum care or do not want to answer the question - you will be taken to the next section Skip to question 73.

\section{Postpartum Inpatient Care}

\section{Comparing Asian Indian women to women of other race- ethnic groups you provide care for}

For each healthcare issue below, please rate them based on whether they occur less or more frequently among Asian Indian women compared to women of other race-ethnic group in your practice:

1 - Occurs significantly LESS often in Asian Indian women

2 - Occurs somewhat LESS often in Asian Indian women

3 - Occurs at the SAME rate in Asian Indian women as the rest of population

4 - Occurs somewhat MORE often in Asian Indian women

5 - Occurs significantly MORE often in Asian Indian women

Please leave blank if not applicable or you do not have an answer ---

60. Defer to family for making decisions regarding her own care

Mark only one oval.

$\begin{array}{lllll}1 & 2 & 3 & 4 & 5\end{array}$

significantly less often in

Asian Indian women
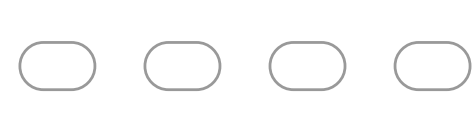

significantly more

often in Asian

Indian women

61. Defer to family for making decisions regarding baby care

Mark only one oval.

$\begin{array}{lllll}1 & 2 & 3 & 4 & 5\end{array}$

significantly less often in

Asian Indian women
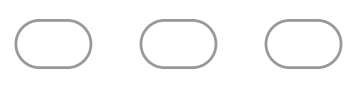

significantly more

often in Asian

Indian women 
62. Appear reluctant to take care of self

Mark only one oval.

significantly less often in
Asian Indian women

63. Show increased anxiety regarding ability to breastfeed

Mark only one oval.

$\begin{array}{lllll}1 & 2 & 3 & 4 & 5\end{array}$

significantly less often in

Asian Indian women

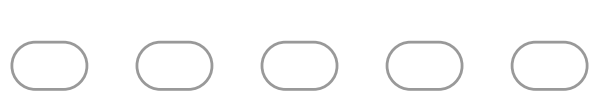

significantly more

often in Asian

Indian women

64. Appear reluctant to take care of baby and ask the staff to perform baby care Mark only one oval.

significantly less often in
Asian Indian women

65. Have many complaints regarding physical discomforts

Mark only one oval.

$\begin{array}{lllll}1 & 2 & 3 & 4 & 5\end{array}$

significantly less often in

Asian Indian women

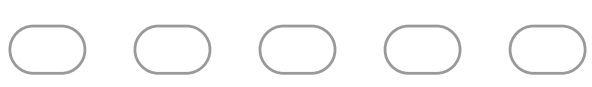

significantly more

often in Asian

indian women

66. Are hesitant to take pain medications

Mark only one oval.

$\begin{array}{lllll}1 & 2 & 3 & 4 & 5\end{array}$

significantly less often in

Asian Indian women

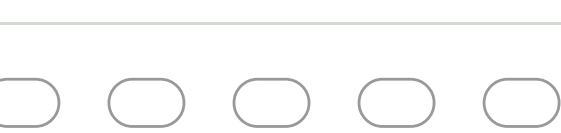

significantly more

often in Asian

Indian women 
67. Plan to breastfeed baby

Mark only one oval.

significantly less often in
Asian Indian women

68. Are likely to start supplementing "to make sure baby is getting enough" Mark only one oval.

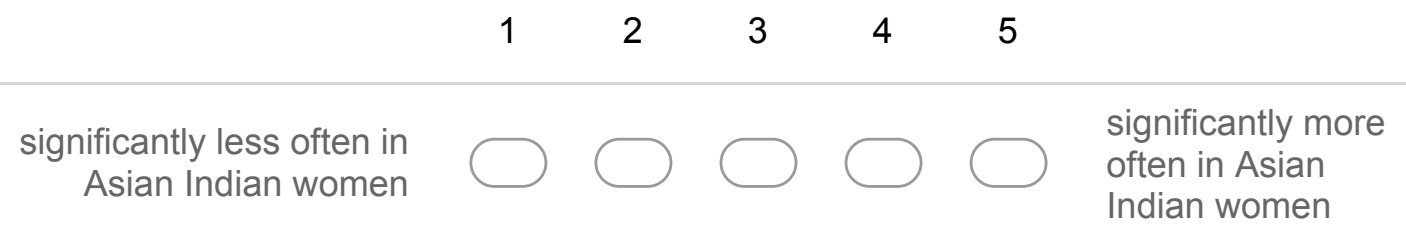

69. Tend to ask the same questions many times

Mark only one oval.

$\begin{array}{lllll}1 & 2 & 3 & 4 & 5\end{array}$

significantly less often in Asian Indian women

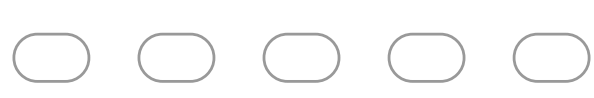

significantly more often in Asian Indian women

70. Seem to be reluctant to go home at the time of discharge

Mark only one oval.

significantly less often in
Asian Indian women

71. Plan to rely on family members for the care of the baby

Mark only one oval.

$\begin{array}{lllll}1 & 2 & 3 & 4 & 5\end{array}$

significantly less often in

Asian Indian women

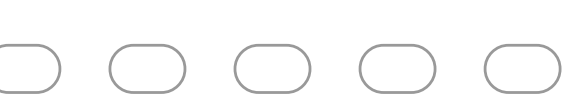

significantly more

often in Asian

Indian women 
72. Ask staff for help in managing extended family Mark only one oval.

significantly less often in
Asian Indian women

\section{Thank you for taking the time to answer the survey!}

Please answer the last three questions below and SUBMIT the survey

73. Do you feel that it is more difficult or less difficult for you to establish therapeutic relationship with Asian Indian patients? Why?

74. What do you think the hospital can do to improve experiences of Asian Indian patients in maternal-child health area?

75. If you feel that there is more information that you want to provide, please enter it below.

When finished, please don't forget to SUBMIT your survey! 